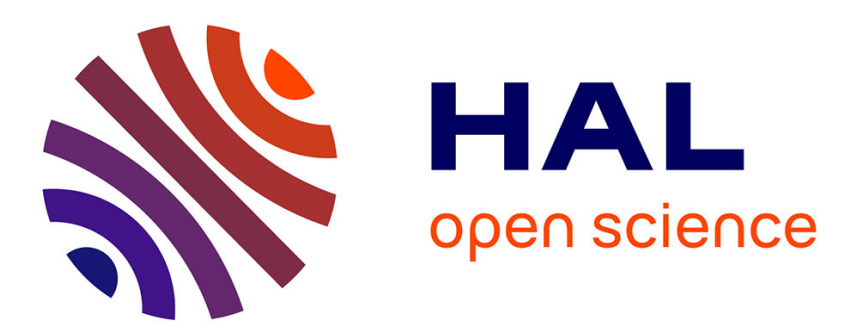

\title{
Playing with chemistry in supercritical solvents and the associated technologies for advanced materials by design
}

Cyril Aymonier, Gilles Philippot, Arnaud Erriguible, Samuel Marre

\section{To cite this version:}

Cyril Aymonier, Gilles Philippot, Arnaud Erriguible, Samuel Marre. Playing with chemistry in supercritical solvents and the associated technologies for advanced materials by design. Journal of Supercritical Fluids, 2018, 134, pp.184-196. 10.1016/j.supflu.2017.12.021 . hal-01783915

\section{HAL Id: hal-01783915 \\ https://hal.science/hal-01783915}

Submitted on 15 Jun 2021

HAL is a multi-disciplinary open access archive for the deposit and dissemination of scientific research documents, whether they are published or not. The documents may come from teaching and research institutions in France or abroad, or from public or private research centers.
L'archive ouverte pluridisciplinaire HAL, est destinée au dépôt et à la diffusion de documents scientifiques de niveau recherche, publiés ou non, émanant des établissements d'enseignement et de recherche français ou étrangers, des laboratoires publics ou privés. 


\title{
Playing with chemistry in supercritical solvents and the associated technologies for advanced materials by design
}

\author{
Cyril Aymonier*, Gilles Philippot, Arnaud Erriguible, Samuel Marre
}

CNRS, Univ. Bordeaux, ICMCB, UPR 9048, F 33600 Pessac, France

\footnotetext{
* Corresponding author at: ICMCB-CNRS, 87 avenue du Dr Albert Schweitzer, 33608 Pessac Cedex, France.

E-mail address: cyril.aymonier@icmcb.cnrs.fr (C. Aymonier).
}

\section{Keywords:}

Supercritical fluids

Inorganic nanomaterials

Chemistry

Supercritical fluid chemical deposition

One pot multistep process

\begin{abstract}
A B S T R A C T
This publication concerns the design of advanced nanostructured inorganic materials using supercritical fluids. A brief overview of the different experimental and numerical tools, which are now available for the scientific community and engineers, is proposed giving access to a better understanding but also a better control on material synthesis. The versatility of the supercritical fluids route for the preparation of different natures of inorganic materials is emphasized based on the access to numerous solvents, precursors and their associated chemistries. It is possible to produce materials with physicochemical properties, which can not be obtained with other routes and at large scale. All these chemistries give access to a wide range of nanobricks opening a new area for the preparation of advanced materials by design through the development of one pot multistep processes.
\end{abstract}

\section{Introduction}

The use of supercritical fluids has fascinated many researchers and engineers in the last 40 years with significant developments in nu merous fields such as extraction/impregnation, green chemistry, was tewater treatment with the so called SuperCritical Water Oxidation (SCWO) process, biomass conversion, materials processing and re cycling, etc. Among these application domains, this paper is focused on the use of supercritical fluids for the processing of advanced nanos tructured materials. When supercritical fluids and materials are con cerned, two main kinds of processes have to be considered: i) the processes based on a physical transformation (Rapid Expansion of Supercritical Solution (RESS), Supercritical AntiSolvent (SAS), etc) for which the driving force of the precipitation is a physical phenomenon (fast depressurisation or an antisolvent effect) and ii) the processes based on a chemical reaction for the precipitation/crystallization, which are the result of a chemical reaction inducing the nucleation \& growth phenomena.

This paper is dedicated to a discussion on the formation of inorganic nanomaterials using processes based on a chemical reaction. This technology is developed by different communities: chemists and che mical engineers with strong backgrounds in materials science. For all 
the people involved in this research field, the target is to prepare ad vanced and green materials to answer to the main challenges of our modern society: energy, environment, health and communications. As chemists, we propose to emphasize the important role played by chemistry in the preparation of advanced nanomaterials using the su percritical fluid technology. This is the richness of chemistry through the use of different solvents and precursors, which allows the controlled synthesis of material with various natures among which are oxides, metals, nitrides, sulphides, phosphides, clays, carbon based materials, etc.

The first part of this publication is dedicated to the description of the experimental and modelling tools, which are today available to process nanostructured materials, while allowing understanding and improving the control of their formation. Then the preparation of ad vanced materials in supercritical fluids is discussed from a chemist prospective; the main solvents with the associated reaction(s) are pre sented. To go towards advanced multifunctional materials, it is now necessary to merge the research works performed by people working on the continuous synthesis of nanopowders in supercritical fluids and people working on the supercritical fluid chemical deposition (SFCD) process. Following a presentation of the possibility to design functional materials with the SFCD process from supported nanoparticles to core shell architectures, some future directions will be opened with the de velopment of one pot multistep processes towards advanced materials by design.

\section{An access to numerous processes, experimental and modelling} tools

In the last ten years, significant efforts have been made by the re search groups involved worldwide in the preparation of inorganic and hybrid organic inorganic nanostructures in supercritical fluids, to open the black box of supercritical reactors. After a brief description of the processes currently used to produce advanced materials using super critical fluids, this section proposes a focus on the in situ diagnostic systems, which are available in the tool box of chemists for a better understanding, but also for a better development of innovative mate rials. All these advances in in situ investigations - meaning advances in understanding - allows considering modelling approaches discussed in the last part of this section.

\subsection{Processes to prepare materials in supercritical fluids}

The supercritical hydrothermal flow synthesis (SHFS) has been first reported by Adschiri et al. in the beginning of the 90's [1]. The de veloped experimental set up is described in Fig. 1a. This process is based on the mixing of a cold metal salt aqueous solution with preheated water fed from another line to favour a burst nucleation.

This study was the starting point of numerous research works, mainly performed by chemical engineers, with two principal focus: i) the evaluation of the potentiality of this synthesis method on the pro cessing of many inorganic and hybrid organic inorganic nanomaterials (to date, most of the elements of the periodic table have been tested) with an insight into the understanding of the hydrothermal mechanism and ii) the study of the mixing, which is the key point of this process. Regarding the first point, a recent review paper presents a state of the art of this continuous hydrothermal synthesis of inorganic nanoparticles [2]. The reader can find a significant coverage of the current field of applications for nanomaterials prepared with the SHFS process. The second point, related basically to the mixing of a cold and a hot flow, has been deeply investigated, especially based on the criteria proposed by Lester et al. in 2006 for an ideal design of a mixer [3]. The CFD modelling, as well as the development of in situ observations, have contributed to the design and the optimization of new mixers [4 7]. All the development history of the SHFS technology is based on a coupling chemical engineering/hydrothermal chemistry/materials science. Che mists, especially in our group in Bordeaux, have also developed com plementary routes by coupling chemistry/chemical engineering/mate rials science, where the target is also the preparation of advanced materials. To do so, chemists have proposed other chemical pathways than the hydrothermal chemistry, which can be processed with dif ferent kinds of solvents, not only water. Then, the process can be adapted to this chemistry [8 11]. With this approach, which will be developed in the following of this opinion article, custom built con tinuous flow reactors are developed, as illustrated in Fig. 1b, with the first report on the preparation of nitride using supercritical ammonia [12].

Whatever the approach, significant advances have been proposed in the last ten years for in situ investigations in order to open the black box of the supercritical fluid reactors, as described in the next section.

\subsection{In situ characterization techniques}

To improve the understanding of particles formation at supercritical fluid conditions and to get insights in the processes, it has been ne cessary to develop tools enabling monitoring in real time and in situ several phenomena such as fluid dynamics, thermodynamics and par ticles nucleation and growth. Given that most reactors for im plementing SCFs processes are made of stainless steel or metal alloys, they can be considered as "blind" for most of the conventional char acterization techniques such as $\mathrm{X}$ ray diffraction and absorption or spectroscopy (UV vis, optical characterization, Raman or Infra Red). Therefore, two main adapted reactor materials and designs have been developed, namely: i) sapphire/fused silica capillaries and tubes and ii)
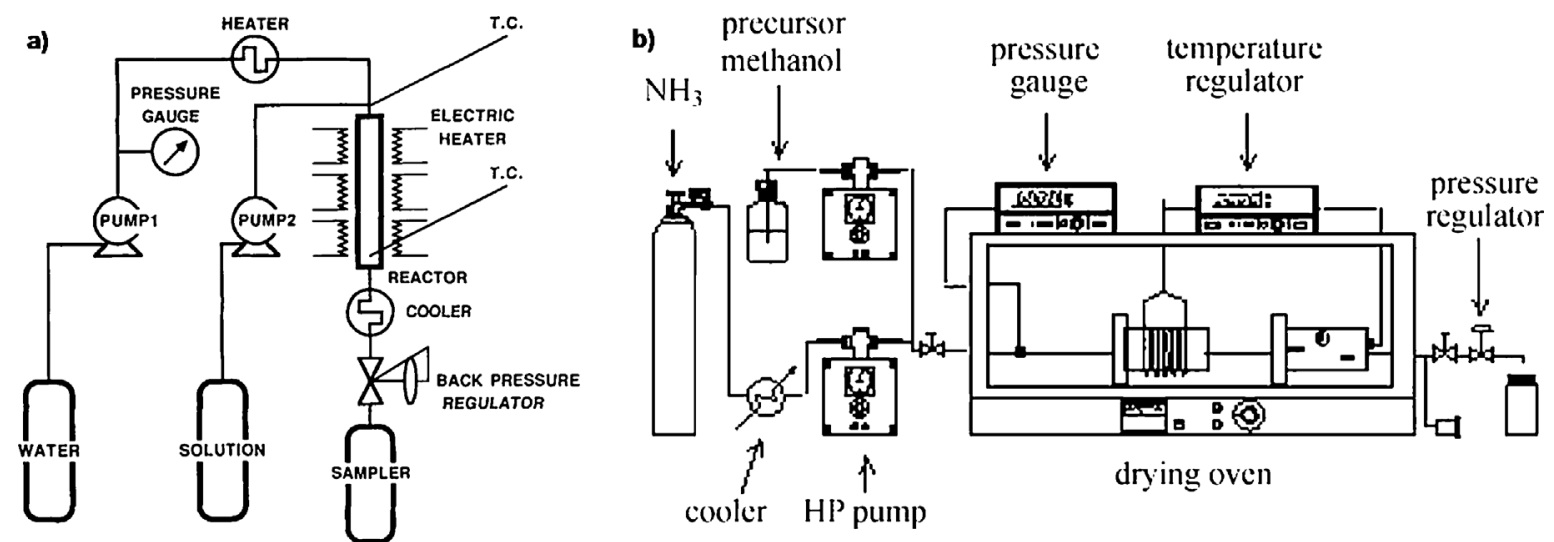

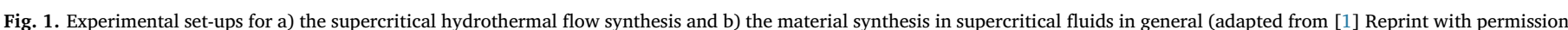

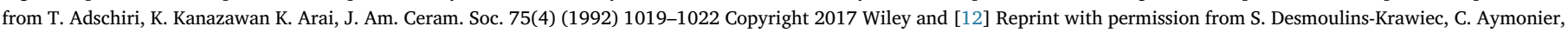
A. Loppinet-Serani, F. Weill, S. Gorsse, J. Etourneau, F. Cansell, J. Mater. Chem. 14 (2004) 228-232 Copyright 2017 Royal Society of Chemistry). 
Synchrotron X-Rays

SAXS / WAXS

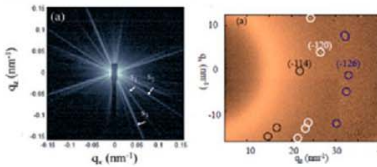

PDF
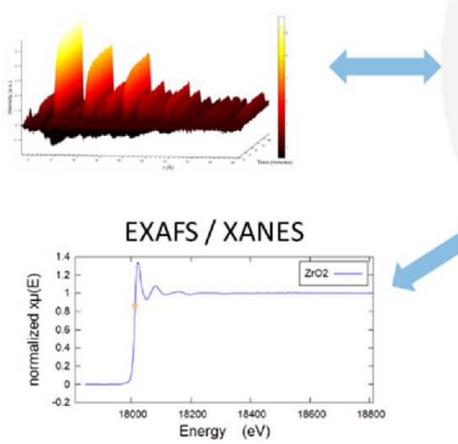

(a)

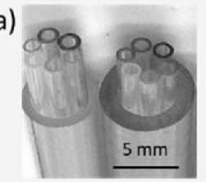

(b)

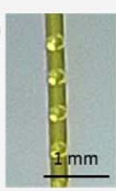

(c)

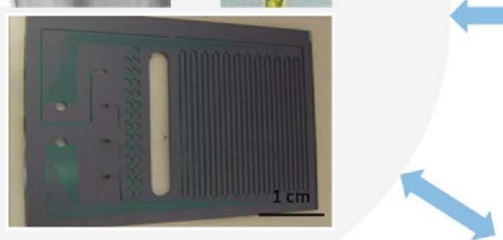

Spectroscopy

Raman

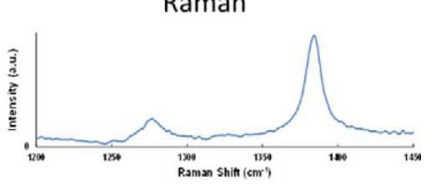

UV-Vis

High speed camera
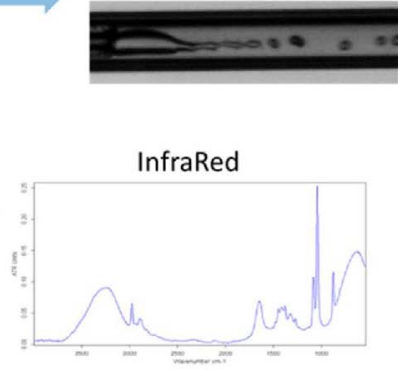

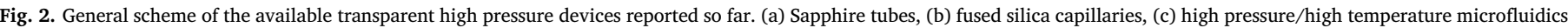
devices with their associated available in situ characterization techniques.

high pressure on chip microreactors.

Sapphire and fused silica tubes (Fig. 2a and b) have been mainly devoted to understand particles formation in near and supercritical aqueous based media since they provide both the transparency and the thermo mechanical resistance to reach these conditions (up to $500{ }^{\circ} \mathrm{C}$ and $30 \mathrm{MPa}$ ). The B. Iversen group has been very active in this field for more than 10 years [13,14]. A typical experiment consists in filling the tube with the precursors and solvents, before being pressurized and heated. The pressure is kept constant during the experiment thanks to the use of a pump working in constant pressure mode. To manage the temperature, the heat can be provided by a simple air blower. Another option consists in designing a stainless steel autoclave that is pressur ized with an inert gas, such as helium, and heated with a furnace. There, the idea is to put a tube containing the precursor solution and pistons in both ends inside the autoclave. When the pressure increases, the pistons move to compress the solution inside the tube $[15,16]$. This strategy does not provide a full access to the reactor over $360^{\circ}$, since there is a need to implement windows in the autoclave, limiting the angular access to the tube. However, the requirements in terms of mechanical strength are lower, opening a number of options regarding the nature of the tube (sapphire, glassy carbon, fused silica, tungsten carbide, etc.) which can be adjusted either to the chemistry or to the characterization technique to be performed. It is important to note that in both cases, the set ups are mostly operated in batch mode, which is different in many points from the flow set ups used to produce powders. To fill this gap, new designs operating in flow and sustaining pressure and temperature have also been proposed based on fused silica capil laries for the synthesis of nanomaterials (Fig. 2b) [17 19].

On chip high pressure microreactors (Fig. 2c) are yet another option for implementing in situ characterization techniques, while offering means to better control parameters such as temperature and feed streams leading to a better reproducibility. The main advantage con cerns the flexibility in terms of design since the use of conventional photolithography microfabrication techniques enables the realization of complex microreactor architectures. Besides, several construction materials can be chosen among such as glass, metal or silicon, providing enough mechanical strength and chemical compatibility to reach con ditions as high as $400{ }^{\circ} \mathrm{C}$ and $25 \mathrm{MPa}$ as well as an easy optical access and transparency [20]. These strategies have been applied to several areas of research [21] such as chemistry, material synthesis [22 24] or supercritical antisolvent processes [25].
Based on these reactor designs, various analyses, from optical to structural ones, can be performed. When speaking of structural ana lyses, in most of the cases, high energy $\mathrm{X}$ ray sources such as syn chrotron are considered to have a good compromise between acquisi tion time and signal resolution. With this tool, it is then possible to perform either in situ $\mathrm{X}$ ray diffraction or $\mathrm{X}$ ray absorption analyses. In the domain of diffraction, it is possible to carry out small and wide angle $\mathrm{X}$ ray diffraction (SAXS/WAXS) measurements but also pair dis tribution function (PDF) ones. The PDF will give information at the molecular level before and during crystallization (so called pre nu cleation clusters) [26 28]. Once the crystallization is initiated, WAXS measurements can be used to provide information regarding particles crystal structures and sizes [29,30]. Eventually, SAXS will give in formation on both the particles size [31], but also the fluid in homogeneities in the near and supercritical domain [32]. The X ray absorption spectroscopy will be complementary to PDF measurements. There, $\mathrm{X}$ ray absorption near edge structure (XANES) and extended $\mathrm{X}$ ray absorption fine structure (EXAFS) can be used to provide informa tion regarding the local environment of a specific atom, even in solu tion. It indicates the nature of the closer neighbors, the coordination number and the geometry [16,33 35]. Combining these various char acterization techniques, it is then possible to catch the full story from pre nucleation organization to nucleation and growth of particles. Be sides sapphire tubes, we have recently demonstrated that such in situ characterization techniques were fully compatible with silicon Pyrex high pressure on chip microfluidic reactors, exemplified by the SAXS and WAXS monitoring of $\mathrm{CaCO}_{3}$ precipitation inside microchannels [36]. In addition to the use of $\mathrm{X}$ ray synchrotron sources, it is also possible to consider other conventional in situ spectroscopy analysis (UV vis, optical characterization, Raman or Infra Red) in order to gain additional information regarding either the structure of the synthesized materials or the chemical engineering parameters (mixing, thermo dynamics, etc. - Fig. 2). For instance, the solubility of $\mathrm{CO}_{2}$ in water was monitored in situ within a microreactor thanks to the use of Raman spectroscopy [37], while high speed imaging was used to determine the dripping to jetting transition at high Reynolds number for coflowing liquid - supercritical fluids at microscale [38,39]. Other examples dealing with extraction or mass transfer processes can be found in some of the reviews of this special issue.

These new developments should open ways towards supercritical fluid processes intensification and a better understanding of the 
involved phenomena. To do so, these data can then be used to feed the numerous models. Indeed, it is critical to couple these experimental tools with simulation for getting insights in some particular mechan isms, which cannot be easily defined and/or understood just through experiments.

\subsection{Modelling and simulation tools}

The optimization of the material synthesis in SCFs depends on a large number of operating parameters and their action on the several phenomena involved in the process, as hydrodynamics, mass transfer, chemical reactivity, phase equilibria and nucleation \& growth of the material to be crystallized. Therefore, it is highly difficult to rationalize the results and to identify the main mechanisms because of the inter actions between parameters. A numerical approach hence becomes fundamental to understand the contribution of the phenomena, to predict the effect of a specific parameter onto the process performance and therefore to optimize the process design. A complete description of the material synthesis process should be able to account for all the physical and chemical phenomena implied in the process.

Generally, the same global strategy was used to simulate the process of particle formation, i.e., the use of the so called Population Balance Equation (PBE) coupled with thermodynamic and hydrodynamic con tributions. The population balance equation is assimilated to a Boltzmann type equation developed by Hulburt and Katz, which allows for determining a statistical distribution of particles in the space [40]:

$$
\begin{aligned}
& \frac{\partial N(L, X, t)}{\partial t}+\nabla \cdot \mathbf{V N}(L, X, t)+\frac{\partial N(L, X, t) G}{\partial L} \\
& \quad=B(L, X, t)-D(L, X, t)
\end{aligned}
$$

In this equation $\mathrm{N}$ represents the number density function, which depends on internal coordinates (particle size L) and external co ordinates (space coordinates $\mathrm{X}(\mathrm{x}, \mathrm{y}, \mathrm{z})$ ). $\mathrm{V}$ is the velocity of the fluid and $\mathrm{G}$ is the growth rate of the particles. The terms in the right hand side are the birth (B) and death (D) rates due to nucleation, agglomeration and breakage. The Eq. (1) can be solved by different numerical techniques, let us cite the most employed ones like the method of classes and the method of moments. More than a numerical challenge, the actual one remains to model the parameters of this equation like the growth rate, the nucleation frequency, the collision frequency for the aggregation and breakage terms. Whereas the concept of population balance was formulated over many years, the implementation of population balance modeling was only recently realized thanks to the rapid development of the computational fluid dynamics (CFD) and the in situ experiments. Indeed, the novel in situ techniques (see Section 2.2) allows measuring the sizes of particles or other variables of interest (velocity, con centration...) in order to provide very interesting data for model parameters estimations and validations. Furthermore, the resolution of the PBE requires to know all the parameters of the process like the fluid velocity, pressure, species concentration and temperature obtained by computational fluid dynamic CFD and the implementation of efficient thermodynamic models in order to calculate the supersaturation, driving force of the crystallization.

To summarize, simulation of materials synthesis in SCF can be achieved in coupling CFD and PBE taking into account efficient ther modynamic models. Numerous techniques for solving PBE are available in the literature, but nowadays the moment methods and its variants (SMOM, QMOM, DQMOM...) appear to be the most suitable techniques while coupling PBE/CFD due to the very low computational time re quired.

Concerning the $\mathrm{CO}_{2}$ based synthesis, only few papers were dedi cated to the simulation of inorganic materials formation in supercritical $\mathrm{CO}_{2}$. The study of Erriguible et al. concerned the synthesis of copper particles in a $\mathrm{CO}_{2} / \mathrm{EtOH}$ mixture in a batch reactor [41]. Only ther modynamic and nucleation \& growth phenomena were taken into account in the simulation as the concentration is assumed to be homogeneous in the vessel. The resolution of the population balance equation, assuming a monodisperse distribution and an instantaneous decomposition of the precursor, takes into account a growth by coa lescence. A similar model was applied to the decoration of silica spheres by copper nanoparticles [42]. The model was based on a bi modal process and takes into account the decomposition kinetic of the pre cursor. A good agreement between the simulated and experimental data is observed showing that there is a kinetically controlled size of the supported copper nanoparticles in the range of temperature $100125^{\circ} \mathrm{C}$ and residence time $0120 \mathrm{~min}$. Similarly, Sierra Pallares et al. proposed a simulation of anatase titanium dioxide synthesis in supercritical $\mathrm{CO}_{2}$ by coupling CFD and PBE assuming a monodisperse distribution [43]. Growth phenomenon is assumed to be due to collision and instant coalescence of particles. The simulation was validated with experi mental results, so the hypothesis of a growth by coalescence seems to be the right one.

The simulation of the supercritical water hydrothermal synthesis has also been the subject of a few studies. In the pioneer work of Adshiri et al., the population balance equation is coupled with CFD to predict the particle size of metal oxide in supercritical water [44]. Solubility data are obtained with the SAA model. In this model, Sue et al. [45] have considered a simplified version of the R HKF model [46], based on the use of different thermodynamic parameters, semi empirical inter action functions, and variables from the Born theory for electrolyte interactions. In this new version, Sue et al. have considered the tem perature density dependence of the semi empirical part of the model, instead of the temperature pressure dependence and have extended the validity domain to the near and supercritical region. The reaction rate is given by a first order Arhenius like correlation. The authors studied two $\mathrm{T}$ junction configurations in order to emphasize the major role of the mixing between the reactant and the supercritical water. The re solution of the PBE with a class method taking into account the ag glomeration of the particles was applied to the hydrothermal synthesis of $\mathrm{TiO}_{2}$ [47]. Classical primary nucleation model and size dependent growth model were used. The authors showed that larger mean particle sizes are produced due to agglomeration. This study was completed by incorporating CFD in the simulation of a counter current reactor to take into account hydrodynamics [48]. The authors used statistic turbulence model $(\mathrm{k} \varepsilon)$ but no specific model of micromixing. Another work fo cused on the impact of the mixing during the synthesis of $\mathrm{CuO}$ nano particles in supercritical water [49]. The classic coupling CFD/PBE was used by integrating the efficient micromixing model for reacting tur bulent flow developed by Fox. It is shown that due to an increase of the Reynolds number and a decrease of the diameter, the mixing time can be reduced, leading to higher nucleation rates and so to smaller parti cles and narrower distributions. Leybros et al. studied the supercritical water synthesis of $\mathrm{ZnO}$ in coupling also CFD and PBE [50]. The solu bility was calculated with the SAA model. The nucleation rate was fitted with experimental results and the authors showed a good qualitative agreement with experiments. More recently, Masoodiyeh et al. simu lated the synthesis of zirconia in supercritical water by using the PBE including the nucleation, the growth and the aggregation terms [51]. They have shown that the concentration and the $\mathrm{pH}$ of the solution can have a significant effect on the particle size distribution.

Finally, all these works emphasize the lack of knowledge concerning the determination of the nucleation and growth parameters. Indeed, the direct experimental determination of such parameters like the fluid solid interfacial tension is still highly challenging. To by pass this issue, one way consists in considering very well controlled experimental conditions like capillary and microfluidic systems coupled with in situ characterization techniques. The real time monitoring of the crystal lization can be then compared to numerical simulation taking into ac count all the chemical and physical phenomena. This interesting ap proach is illustrated by the work of Voisin et al. (Fig. 3) concerning the precipitation of sodium sulfate in supercritical water [52]. The authors 


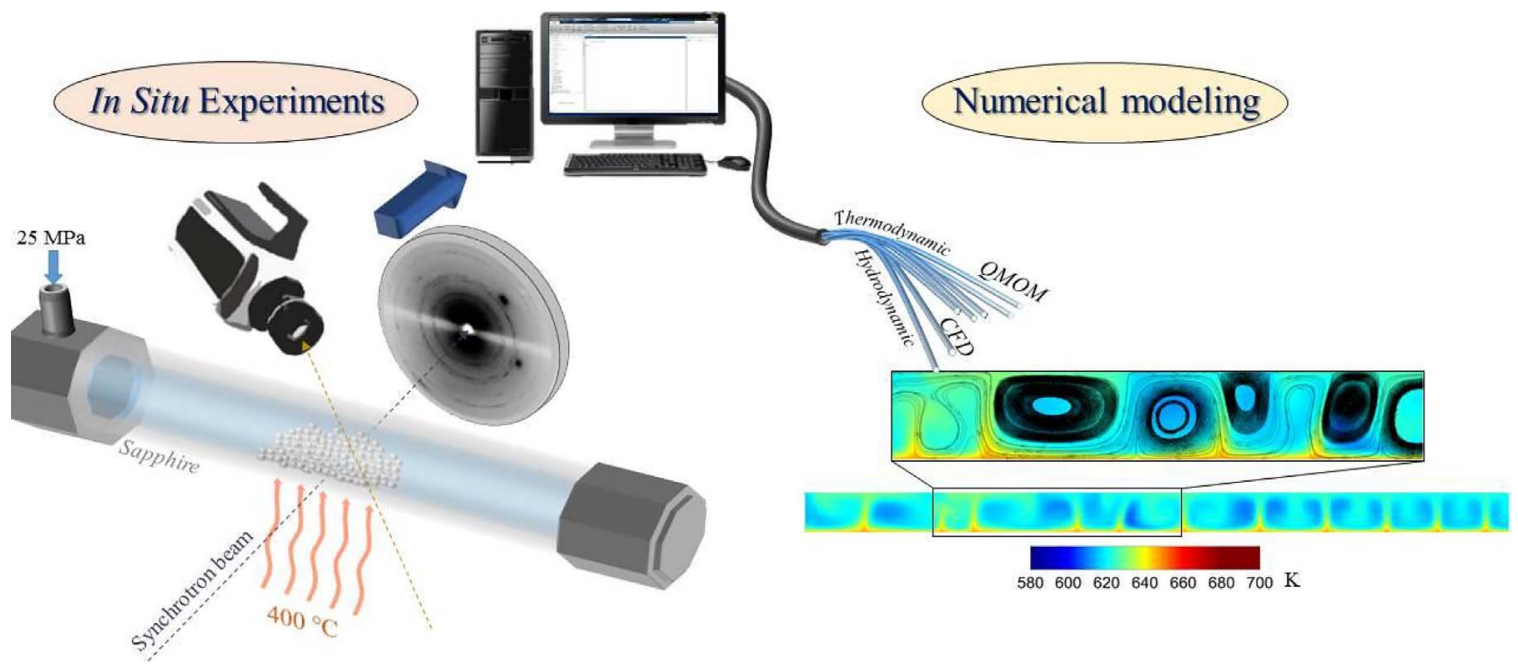

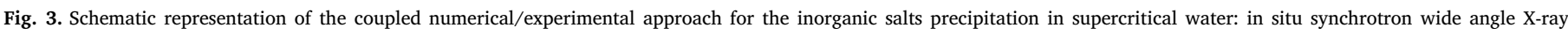

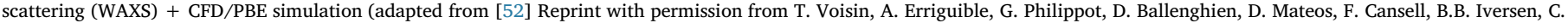
Aymonier, Chem. Eng. Sci. 174 (2017) 268-276 Copyright 2017 Elsevier).

proposed to use an original compressible model, developed for the si mulation of near critical flow, with the population balance equation solved by the standard method of moments [53]. The crystallite size determined with the numerical simulation was compared with the one obtained experimentally with in situ synchrotron wide angle $\mathrm{X}$ ray scattering (WAXS) in order to determine the mass transfer coefficient for the growth rate.

This section proposed a brief overview of the different experimental and numerical tools, which are now available for the scientific com munity and engineers to perform and understand chemistry and nu cleation \& growth in supercritical fluids, especially to design advanced materials. The next section is now going to discuss the preparation of advanced materials from a chemist prospective.

\section{Chemistry in supercritical solvents for the preparation of advanced materials}

Based on more than 25 years of research and development works, the near and supercritical continuous solvothermal method offers a fast, sustainable and scalable route towards high quality nanostructures (NCs), meaning NCs with physico chemical properties, which cannot be obtained, in most of the cases, with other synthetic approaches. The history of this technology was first written with the use of water as solvent through the supercritical hydrothermal flow synthesis (Fig. 1a), which still represents today most of the research activities. In the last 10 years, the use of supercritical water as solvent was extended to other fluids like alcohols, $\mathrm{NH}_{3}$, alkanes, $\ldots$ and mixtures of them. The critical coordinates of the most common used solvents are summarized in Table 1 . This extension by chemists to other solvents and mixtures of them for the supercritical continuous process has contributed to in crease the versatility of this material processing approach.

Regarding mixtures, only few thermodynamic data are reported in the literature, like for the water/ethanol binary mixture [56]. Thanks to the development of advanced in situ diagnostic tools such as super critical microreactors, the thermodynamic of complex mixtures is now accessible in short time [57].

\subsection{Chemistry in supercritical water}

As already discussed in Section 2.1, the supercritical hydrothermal flow synthesis (SHFS) has been actively developed for many years on the basis of a well know hydrothermal mechanism (hydrolysis and dehydration) [1]:
Table 1

Critical coordinates of the solvents mentioned in this article [54,55].

\begin{tabular}{llll}
\hline Solvents & $\mathrm{T}_{\mathrm{c}}\left({ }^{\circ} \mathrm{C}\right)$ & $\mathrm{p}_{\mathrm{c}}(\mathrm{MPa})$ & $\rho_{\mathrm{c}}\left(\mathrm{kg} \mathrm{m}^{3}\right)$ \\
\hline Carbon dioxide & 31 & 7.38 & 468 \\
Water & 374 & 22.06 & 322 \\
Methanol & 239 & 8.10 & 276 \\
Ethanol & 241 & 6.27 & 273 \\
Propanol & 264 & 5.17 & 274 \\
Isopropanol & 235 & 4.76 & 273 \\
Butanol & 290 & 4.42 & 270 \\
Pentanol & 313 & 3.88 & 270 \\
Hexanol & 338 & 3.51 & 268 \\
Ammonia & 132 & 11.33 & 225 \\
Hexane & 235 & 3.03 & 233 \\
Cyclohexane & 280 & 4.08 & 291 \\
Toluene & 319 & 4.14 & 235 \\
Octane & 296 & 2.50 & \\
\hline
\end{tabular}

$\mathrm{M}\left(\mathrm{NO}_{3}\right)_{\mathrm{x}}+\mathrm{xH}_{2} \mathrm{O} \Leftrightarrow \mathrm{M}(\mathrm{OH})_{\mathrm{x}}+\mathrm{xHNO}_{3}$

$\mathrm{M}(\mathrm{OH})_{\mathrm{x}} \Leftrightarrow \mathrm{MO}_{\mathrm{x} / 2}+\mathrm{x} / 2 \mathrm{H}_{2} \mathrm{O}$

Beyond the processing of numerous kinds of metal oxide nano particles, the in situ functionalization with organic moieties has also been largely investigated [58 60].

Recently, we have demonstrated the first proof of the synthesis in few tens of seconds of clay minerals in supercritical water, namely talc, using a continuous process [61,62]. The mechanism involves first the formation of a talc precursor, so called prototalc, following this equa tion:

$4\left(\mathrm{Na}_{2} \mathrm{SiO}_{3}\right)+3\left(\mathrm{Mg}\left(\mathrm{CH}_{3} \mathrm{COO}\right)_{2}\right)+2\left(\mathrm{CH}_{3} \mathrm{COOH}\right)+\mathrm{mH}_{2} \mathrm{O} \rightarrow$

$\mathrm{Si}_{4} \mathrm{Mg}_{3} \mathrm{O}_{11}, \mathrm{nH}_{2} \mathrm{O}+8 \mathrm{CH}_{3} \mathrm{COONa}+(\mathrm{m} \mathrm{n}+1) \mathrm{H}_{2} \mathrm{O}$

with $\mathrm{m}$ and $\mathrm{n}$ as integers.

Then, the talc crystallization occurs in supercritical water. The re duction of synthesis steps and the use of supercritical water offer a major technical breakthrough since it allows decreasing the synthesis time from several hours to tens of seconds. This innovative route offers the possibility to obtain a range of nanominerals differing in their de gree(s) of crystallinity and size just by adjusting synthesis time and/or temperature. Beyond the control of these characteristics, this synthetic talc exhibits unique properties as its hydrophilicity. The hydrophilic character of this synthetic talc has conducted to the formulation of the first fluid talc filler. A scale up of the talc synthesis is currently under 

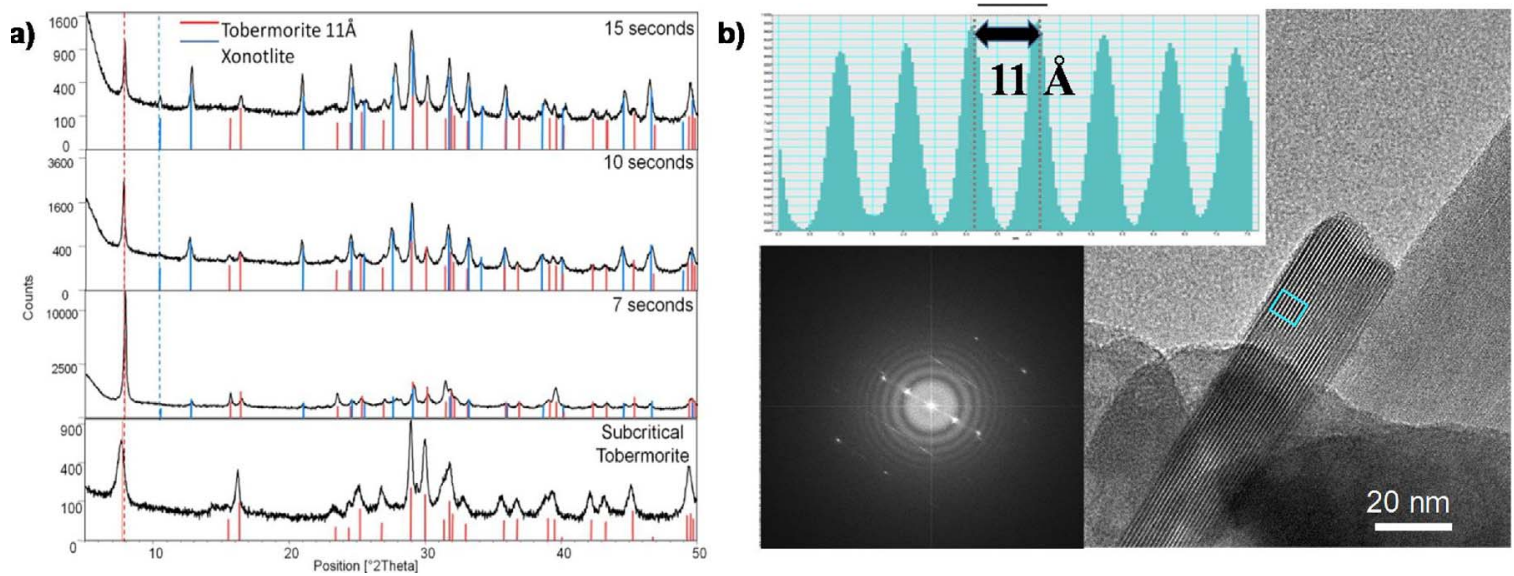

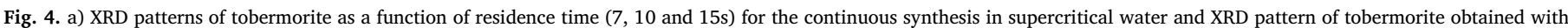

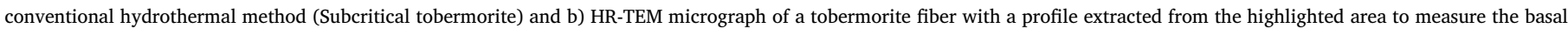

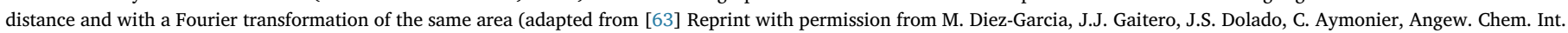
Ed. 56 (2017) 1-6 Copyright 2017 Wiley).

\section{progress.}

Beyond chemistry, reaction kinetics represent a key issue. More recently, we went one step forward with the demonstration to prepare other highly crystalline geominerals in just a few seconds but under thermodynamically metastable conditions [63]. This result was ob tained with the metastable calcium silicate, the tobermorite. A fine control of reaction kinetics prevents the formation of the most ther modynamically stable phase, which is the xonotlite as illustrated in Fig. 4. Torbermorite mineral is not abundant in nature but very inter esting in the construction industry. As a result of the supercritical continuous hydrothermal synthesis, highly crystalline fibrillar to bermorite can be obtained similar to what nature can produce.

Although chemistry in supercritical water is investigated since the beginning of the 90 's for the processing of advanced inorganic mate rials, these recent results prove that there is still plenty of works to be perform in this extraordinary solvent that is water. Adding alcohol in water gives access to another kind of chemistry, the so called sol gel chemistry.

\subsection{Sol gel like chemistry in water alcohol systems}

Sol gel chemistry is generally considered as a soft chemistry route and has been developed for a long time [64]. The well known me chanism is based on two steps: hydrolysis and condensation. Sol gel chemistry in supercritical fluid conditions has been developed with the introduction of chemistry in supercritical water alcohol mixtures [65 67]. Sol gel like chemistry in supercritical water alcohol mixtures can be of great interest since the produced particles present very little defects in terms of vacancies, purity or amorphization with a control over the material composition for polycationic oxides. One of the most widely investigated material in supercritical sol gel chemistry is the $\mathrm{BaTiO}_{3}$ and its derivatives (A site substitution with $\mathrm{Ba}_{1 \mathrm{x}} \mathrm{Sr}_{\mathrm{x}} \mathrm{TiO}_{3}$ (BST $0 \leq \mathrm{x} \leq 1$ ) and $\mathrm{B}$ site substitution with $\mathrm{BaTi}_{1} \mathrm{Zr}_{\mathrm{y}} \mathrm{O}_{3}$ (BTZ $0 \leq \mathrm{y} \leq 1)$ ) $[29,68,69]$. In 1999, Bocquet et al. opened the way pro ducing $10 \mathrm{~nm} \mathrm{BaTiO}$ nanocrystals in flow, starting with barium and titanium double alkoxide in an isopropanol/water mixture [65]. Since 2005, our group has developed this two lines injection process (Fig. 5a), starting with barium and titanium isopropoxides dissolved in absolute ethanol in one line and mixed just before the main reactor with a second line of preheated water at $150{ }^{\circ} \mathrm{C}$. The gel that is formed goes inside the reactor where the temperature is $400{ }^{\circ} \mathrm{C}$ and the pressure $23 \mathrm{MPa}$ for a residence time close to one minute $[66,67]$. There, we showed that adjusting the ethanol/water molar ratio to 0.29 , it was possible to produce, in a single step, high quality nanocrystals with a main size around $20 \pm 6 \mathrm{~nm}$ (Fig. 5b). Once the synthesis of pure
$\mathrm{BaTiO}_{3}$ has been controlled, we first extended our research to the synthesis of BST nanocrystals using strontium isopropoxide as supple mentary precursor [67]. To go deeper into the understanding of the material formation in such conditions, in situ synchrotron study was considered, to follow in real time the nanocrystals formation (Fig. $5 \mathrm{c}$ ) by using wide angle $\mathrm{X}$ ray scattering (WAXS). Coupling these results with supplementary ex situ analyses such as spectroscopy, it was pos sible to show that the variation of the nanocrystal growth upon stron tium content was related to the amount of surface $-\mathrm{OH}$ defects, itself depending on the strontium amount [29]. Then, focusing on the $\mathrm{Ba}_{0.6} \mathrm{Sr}_{0.4} \mathrm{TiO}_{3}$ sample, we were able to make dense (more than $90 \%$ ) and nanostructured ceramics, keeping the initial grain size, using spark plasma sintering (Fig. 5d), to characterize the intrinsic dielectric properties of the powder [70]. Dielectric measurements on these pellets proved, for the first time, the existence of ferroelectricity at the $20 \mathrm{~nm}$ scale, confirming the unique quality of both, the nanocrystals and the ceramics. Finally, to get a global view on the potential of this particular synthesis at a larger scale, we reported the first study presenting the life cycle assessment (LCA) of metal oxide nanoparticles produced using sol gel like chemistry in supercritical fluids, using the specific case of BST [71]. With the hypothesis of an optimized industrial scale production, we were able to highlight the critical impact of the precursor choice on the LCA. Indeed, the use of alkoxides was evidenced as being the main contribution (more than $60 \%$ and up to $85 \%$ ) on most of the indicators such as climate change, fossil, metal or water depletions, etc. Then comes the use of solvent with up to $20 \%$ of contribution and the process running costs (energy, etc.) with $520 \%$ contribution depending on the indicators.

Beyond the sol gel like chemistry, chemistry in supercritical water alcohol mixtures is fascinating because the influence of the solvent composition on the material formation has been put in evidence but is not really understood. Another example is the formation of $\gamma \mathrm{Al}_{2} \mathrm{O}_{3}$ in water/isopropanol mixture [72]. Without water, no crystalline struc tures are observed, with $7 \mathrm{vol} . \%$ of water, $\gamma \mathrm{Al}_{2} \mathrm{O}_{3}$ is obtained and with $13 \mathrm{vol} . \%$ of water, $\mathrm{AlOOH}$ is formed. Therefore, several questions have arisen from these observations: why 7 vol.\% of water for $\gamma \mathrm{Al}_{2} \mathrm{O}_{3}$ ? Why 0.29 molar ratio for $\mathrm{BaTiO}_{3}$ ? etc. An answer can be probably found at the molecular level looking at the organization of molecules in the water/alcohol mixtures.

\subsection{Thermal decomposition in supercritical alcohols}

The research works on the investigation of the sol gel like chemistry in supercritical water ethanol mixtures, especially on the formation of $\mathrm{BaTiO}_{3}$ based nanoparticles, brought us to consider the nucleation \& 

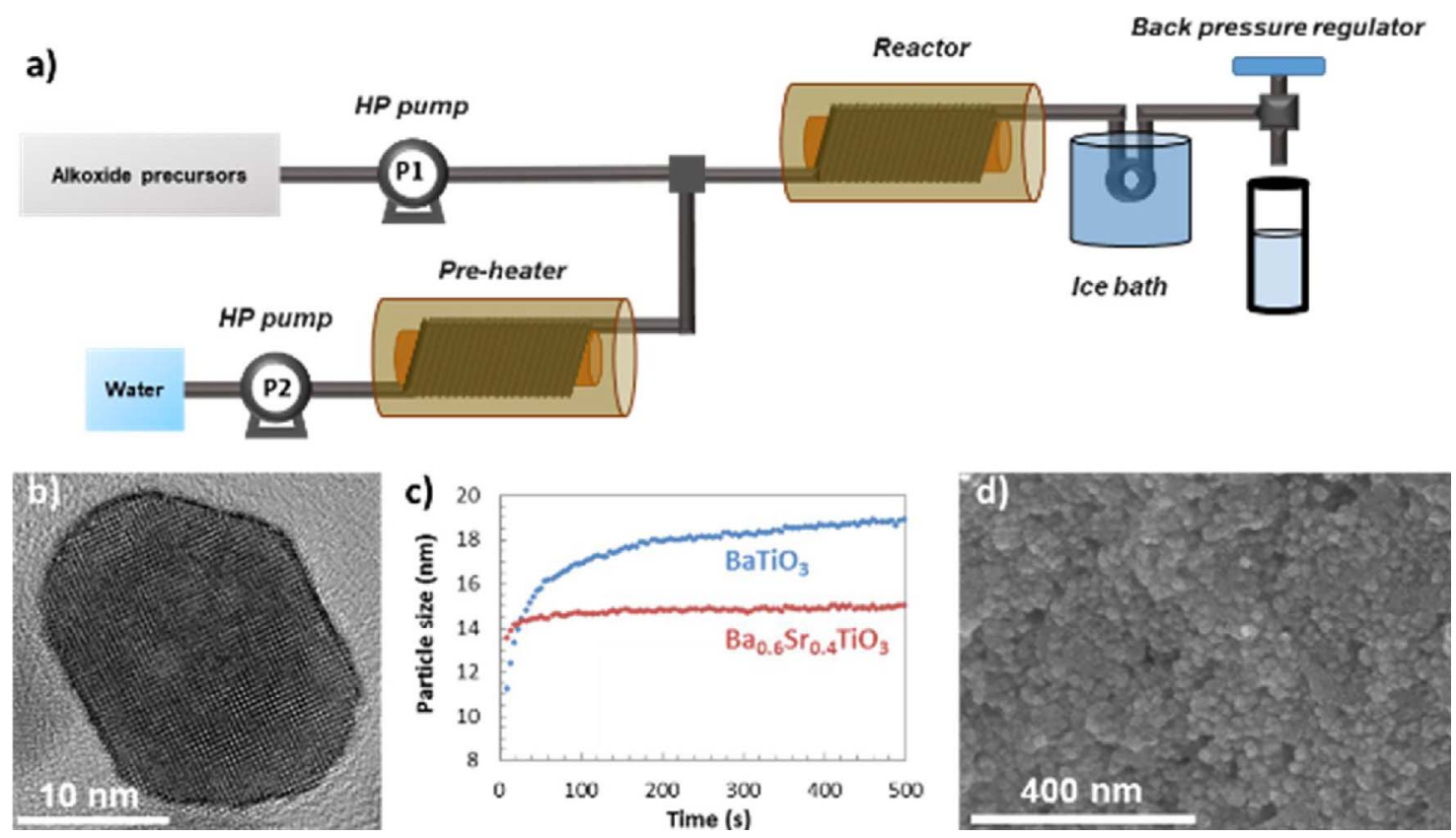

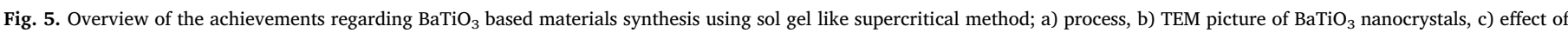
strontium on nanocrystals growth and d) SEM picture of $\mathrm{Ba}_{0.6} \mathrm{Sr}_{0.4} \mathrm{TiO}_{3}$ dense and nanostructured ceramic made by SPS.
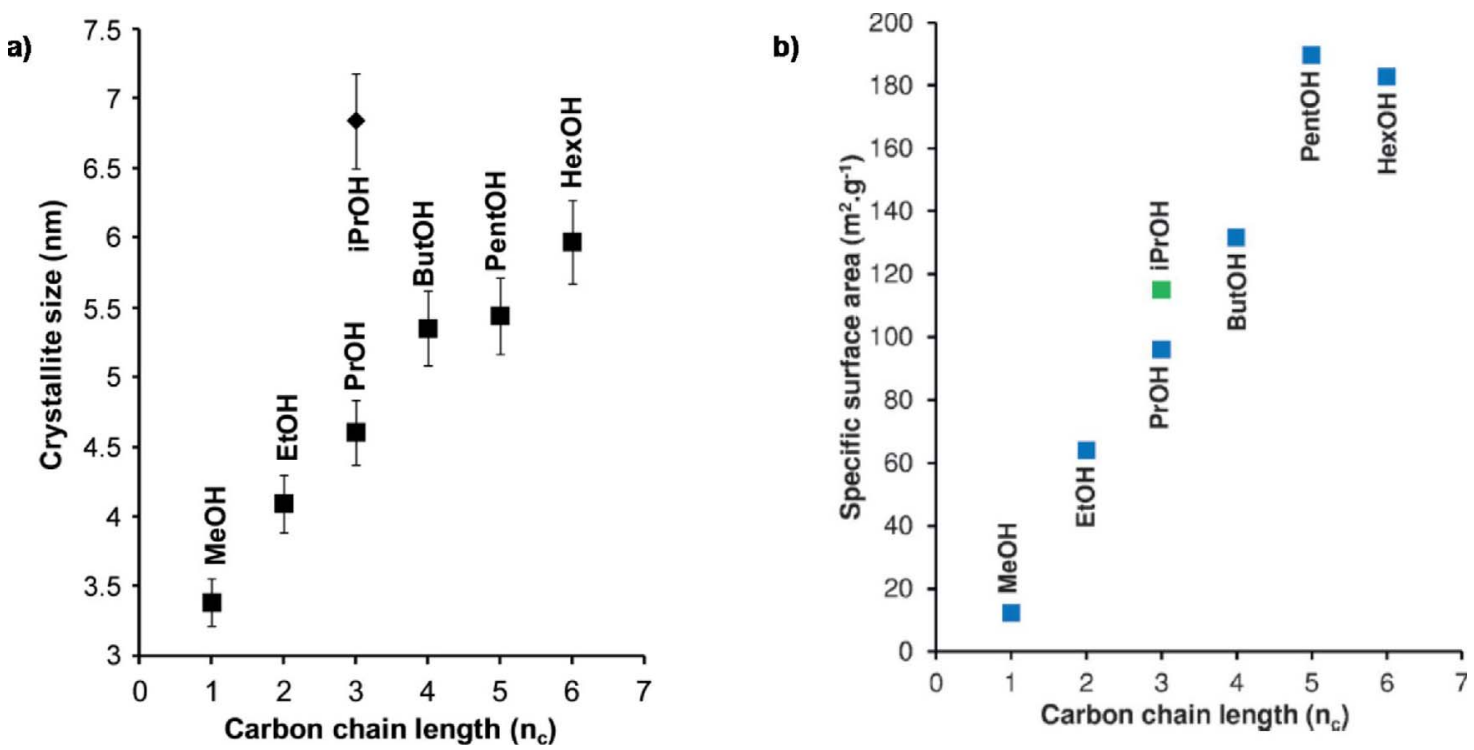

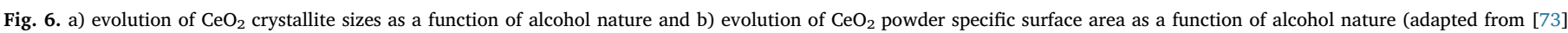

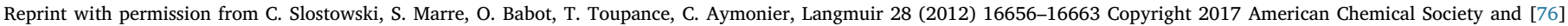
Reprint with permission from C. Slostowski, S. Marre, O. Babot, T. Toupance, C. Aymonier, Chem. Phys. Chem. 16 (2015) 3493-3499 Copyright 2017 Wiley).

growth of nanostructures in supercritical alcohols on $\mathrm{CeO}_{2}$ as a model material [73]. It is important to underline that the thermal stability of alcohols needs to be considered in studying reactivity in supercritical alcohols [74]. We have studied the thermal decomposition of the am monium cerium (IV) nitrate at $300{ }^{\circ} \mathrm{C}$ and $24.5 \mathrm{MPa}$ in seven different alcohols being $\mathrm{MeOH}$, EtOH, PrOH, iPrOH, ButOH, PentOH and $\mathrm{HexOH}$. Nanopowders with different characteristics were obtained in comparison with the reference obtained in water. This really illustrates the interest of playing with supercritical solvents to change the chem istry and also the material characteristics. The $\mathrm{CeO}_{2}$ nanopowders are constituted of spherical aggregates of $\mathrm{CeO}_{2}$ nanostructures for which the size depends on the alcohol used (Fig. 6a) in the range of $37 \mathrm{~nm}$. The second important result was the surface functionalization of $\mathrm{CeO}_{2}$ nanocrystals with organic moieties (mainly alkoxide and carboxylate bonding) coming from alcohols meaning that the alcohols are playing the role of solvent and functionalizing agents. A direct correlation be tween the grafting density and the alcohol chain lengths can be es tablished: the shorter the alcohol chain, the higher the surface coverage [75]. This trend allows explaining the evolution of the $\mathrm{CeO}_{2}$ crystallite size as a function of the alcohol nature. The grafting of molecules at the surface of $\mathrm{CeO}_{2}$ nanocrystals has also a significant effect on their thermal stability [76]. When submitted to a thermal treatment at $500{ }^{\circ} \mathrm{C}$, surface organic moieties desorb/degrade in a different way depending on the alcohol nature. A sintering of $\mathrm{CeO}_{2}$ powders prepared in sc $\mathrm{MeOH}$, sc EtOH and sc iPrOH is observed leading to a decrease of their specific surface area. Conversely, those produced in sc $\mathrm{BuOH}, \mathrm{nc}$ PentOH and nc HexOH keep their initial crystallite sizes and show a great enhancement of their specific surface area (up to $200 \mathrm{~m}^{2} \mathrm{~g}^{-1}$ ). A so high specific surface area for $\mathrm{CeO}_{2}$ treated at $500{ }^{\circ} \mathrm{C}$ is not so common; powders are stabilized by the longest carbon chain alcohols. 
These behaviors are represented in Fig. 6b. These materials with high specific surface areas can be interesting solid sorbent for efficient $\mathrm{CO}_{2}$ capture/release processes [77].

The results obtained with ceria were confirmed in a study of the influence of the nature of alcohols on the nucleation \& growth of NiMo, a catalyst precursor for hydrodesulfurization of petroleum, in super critical water alcohol mixtures [78]. The nature of the alcohol used plays a major role on the specific surface area, that increases from a value of $79 \mathrm{~m}^{2} \mathrm{~g}^{-1}$ using methanol as solvent up to $179 \mathrm{~m}^{2} \mathrm{~g}^{-1}$ using isopropanol as solvent.

Supercritical alcohols represent an interesting family of solvents, which has gathered more and more attention over the last 10 years with an increasing number of publications [73 82, etc]. Alcohols are less polar than water and can be reducing solvents that can generate water in situ by dehydration and allow performing thermal decomposition reactions, etc, all these phenomena being tuned playing with the nature of the alcohols.

\subsection{Chemistry in other supercritical solvents}

Besides water and alcohols - and their associated mixtures - other supercritical solvents and mixtures have been used for the continuous flow synthesis of materials. There are several motivations for their use such as precursors' solubility considerations, chemical compatibilities (for instance the need for non oxygenated solvents when considering air sensitive processes) or thermo kinetics. Therefore, several examples were reported considering either $\mathrm{CO}_{2}[83,84]$, alkanes $[85,86]$ or aro matics [87] supercritical solvents.

As an example, we have demonstrated the use of a coflowing set up to continuously synthesize hybrid Pd nanocatalysts (Fig. 7a) [18]. A palladium precursor (Palladium hexafluoroacetylacetonate - Pd $(\mathrm{hfac})_{2}$ ) dissolved in toluene was reduced by hydrogen in order to prevent from any contamination of the Pd NCs surface by other redu cing reagents. To address the Pd precursor diffusion limited reduction reaction with $\mathrm{H}_{2}$ (due to the low solubility of hydrogen in toluene in our conditions: $\mathrm{T}=100^{\circ} \mathrm{C}-\mathrm{p}=25 \mathrm{MPa}$ ), supercritical $\mathrm{CO}_{2}$ was added to the system as the main solvent to ensure a single phase reaction, thus getting rid of gas liquid mass transfer limitations. The coflow config uration allowed to separate the nucleation \& growth process from the functionalization step in a better way than previously reported [88]. This way, various types of ligands were tested and successfully linked to the Pd NCs, resulting in the synthesis of a "ready to use" nanocatalysts solution in short time (residence time of $17 \mathrm{~s}$ ). This approach allowed to access a library of nanocatalysts (varying only the ligands system), whose catalytic efficiencies were further evaluated towards the C B coupling process in the Vaultier reaction $[89,90]$.

The case of inorganic semiconductors nanoparticles (quantum dots - QDs) synthesis in supercritical fluids is also of interest. Indeed, the properties of SCFs can be used to address some of the limitations of conventional glassware solution chemistries by narrowing the size distribution (which is a critical characteristic to master for QDs since most of the applications require narrow line width emission, directly dependent on the size distribution) and by enhancing the reproduci bility. The first demonstration was reported with the synthesis of CdSe QDs in supercritical hexane within high pressure microfluidic reactors. Precursors cadmium oleate $\left[\mathrm{Cd}(\mathrm{ol})_{2}\right]$ and trioctylphosphine selenium [TOPSe] in hexane were mixed directly at high temperature and high pressure $\left(270<\mathrm{T}<310^{\circ} \mathrm{C}, \mathrm{p}=5 \mathrm{MPa}\right)$ leading to fast nucleation of QDs [22]. The supercritical fluid synthesis produced a narrower full width at half maximum (FWHM) photoluminescence and particles size distribution compared to liquid phase synthesis in the same conditions, demonstrating that the use of supercritical solvents effectively results in homogeneous reaction conditions ideal for nanocrystals synthesis [23].

Based on this first demonstration, Baek et al. proposed a continuous three stage silicon based supercritical microfluidic systems process ( $\mathrm{p}=6.5 \mathrm{MPa})$ consisting in mixing $\left(130175^{\circ} \mathrm{C}\right)$, aging $\left(200340^{\circ} \mathrm{C}\right)$, and sequential injection stages $\left(80320^{\circ} \mathrm{C}\right)$ for the production of high quality InP nanocrystals in supercritical octane from precursors indium myristate $\left[\mathrm{In}(\mathrm{MA})_{3}\right]$ and tris(trimethylsilyl) phosphine [(TMS $\left.)_{3} \mathrm{P}\right]$ [91]. Further developments have shown that the production of high quality QDs in supercritical fluids processes was easily scalable to gram scale [92,93]. More recently, the access to unconventional conditions pro vided by supercritical fluids processes was used to synthesize con tinuously gallium nitride QDs from the decomposition of a single source
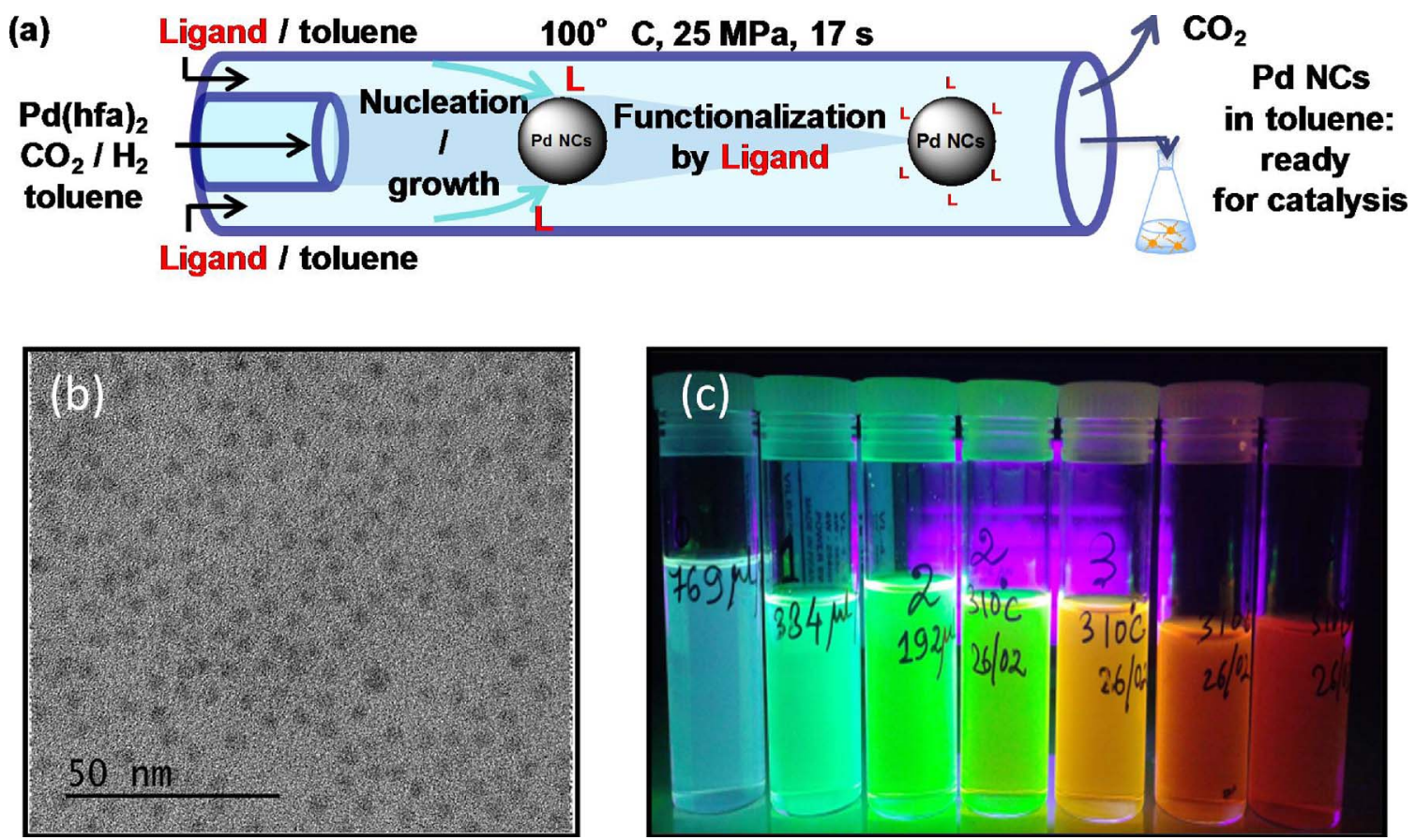

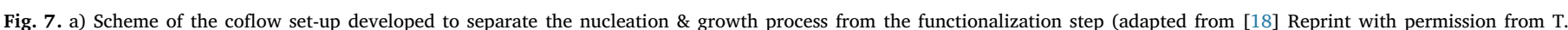

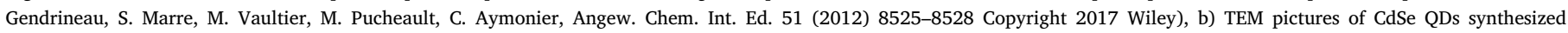
continuously in supercritical hexane and c) associated pictures of various sizes of CdSe QDs solutions under UV irradiation $\left(\lambda_{\mathrm{Ex}}=365 \mathrm{~nm}\right)$. 
precursor (tris dimethylamido gallium $\left[\mathrm{Ga}\left[\mathrm{N}\left(\mathrm{CH}_{3}\right)_{2}\right]_{3}\right]_{2}$ ) in either pure supercritical cyclohexane or in a supercritical mixture cyclohexane/ ammonia [94]. Quantum confined nanoparticles (2 $3 \mathrm{~nm}$ in diameter) with narrow size distributions were produced continuously in short times (30s), exhibiting exciton photoluminescence in the UV region $(\lambda=300 \mathrm{~nm})$.

The aforementioned section demonstrates the versatility of the su percritical fluids route for the preparation of different natures of in organic materials. This is made possible by playing with a rich chem istry, meaning with solvents under pressure and temperature and precursors. This approach gives access to high quality nanostructures materials (among oxides, polycationic oxides, metals, nitrides, phos phides, sulfides, clays, carbon based materials...), which are highly crystalline with controlled composition, size and surface properties (from neat to functionalized surfaces, not described in this paper [95]). It is possible to prepare materials with physicochemical properties which cannot be obtained with other routes and at large scale. All these chemistries give now access to a wide range of nanobricks opening a new area for the preparation of advanced materials by design.

\section{From supported nanoparticles to core-shell architectures}

A part of the research works of the supercritical fluids community in the field of materials science is dedicated to the homogeneous nuclea tion \& growth of nanopowders as described in the previous section. Another part is interested in the development of the so called Supercritical Fluid Chemical Deposition (SFCD) method or Supercritical Fluid Reactive Deposition (SFRD) process for the synthesis of supported mono and bimetallic nanoparticles [96 100]. Two strategies are commonly employed: (i) a kinetically controlled process and (ii) a thermodynamically controlled process (this latter will be discussed in another paper of this special issue of the Journal of Supercritical Fluids by M. Türk and C. Erkey). The kinetically controlled approach was initially exemplified with the decoration of silica nanospheres with copper nanoparticles. To do so, silica particles were suspended within $\mathrm{CO}_{2}$ alcohols supercritical mixtures (methanol, ethanol or isopropanol) in presence of a copper precursor (copper hexafluoroacetylacetonate $\mathrm{Cu}(\mathrm{hfac})_{2}$ ) and hydrogen, used as the reducing agent. A tunable amount of coverage between 40 and $80 \%$ was achieved and the average copper nanoparticle sizes were ranging between 5 and $17 \mathrm{~nm}$ (Fig. 8a) [101]. The deposition mechanism was investigated by modelling. The surface nanostructures formation can be decomposed in a homogeneous nu cleation and a heterogeneous growth induced by a chemical reaction through a bi modal process, as mentioned in Section 2.3 (Fig. 8c) [42]. The SCFD process was later applied to the development of advanced nanostructured materials for hydrogen storage application [102 104] or still catalysis [105]. In particular, this process was applied to the surface decoration of magnesium crystals (known to be able to ac commodate up to $7 \mathrm{wt} \%$ of $\mathrm{H}_{2}$ in solid state $-\mathrm{MgH}_{2}$ ) with various metal nanoparticles. The main interests concern: (i) the ability of having a synergetic effect between the surface NPs and the Mg crystals to speed up the sorption/desorption kinetics of $\mathrm{H}_{2}$ by $\mathrm{Mg}$ and (ii) the stability of the composite obtained through SFCD process compared to classical ball milling approaches (Fig. 8d). In the case of Mg crystals covered with nickel NPs, we have demonstrated that both the syner getic effect and the stability arise from the creation of an interphase $\left(\mathrm{Mg}_{2} \mathrm{Ni}\right)$ at the interface between $\mathrm{Ni}$ and $\mathrm{Mg}$ (Fig. 8e).

More recently we proposed an alternative process to SFCD to highly dispersed active species [106,107] into a porous support to prepare hydrodesulfurization (HDS) catalyst precursor. The porous support is first impregnated by conventional dry impregnation (or incipient wet ness impregnation) allowing to use precursor(s) and/or salt(s) which are employed at the industrial scale but also to impregnate the support with the desired loading rate (the limitation is imposed by the solubility of the precursor(s)/salt(s) in the impregnation solvent). The im pregnated support is exposed to supercritical $\mathrm{CO}_{2}$ inducing a flash drying/treatment of the impregnated precursor(s)/salt(s) and so the dispersion of the active species onto the support. Such kind of methods conducts to the preparation of highly active catalyst precursor for HDS.

In the last 20 years many works have been dedicated to the pre paration of supported mono and bimetallic nanoparticles as afore mentioned. Our group has also investigated the formation of core shell architecture [108] with the wish to understand how it is possible to go from supported nanoparticles to core shell architectures. We have coated using the SFCD method $\mathrm{BaTiO}_{3}$ ferroelectric nanoparticles of about $50 \mathrm{~nm}$ with a shell of few nanometers of amorphous alumina (Fig. 8b). The sintering of these core shell nanoparticles gives access to a ceramic material with very interesting ferroelectric properties, in particular, dielectric losses below $1 \%$. The formation of a shell is pos sible due to the particle surface reactivity with the used precursor.

Today it is possible to control the formation of nanostructured materials with the SFCD process from supported nanoparticles to core shell architectures. The future is now to take benefit of all these re search works, which have been performed on homogeneous nucleation \& growth of nanopowders and on supported nanoparticles and core shell architecture with the SFCD method to develop one pot multistep processes for the preparation of advanced materials by design.

\section{Challenges and opportunities: one pot multistep processes towards advanced materials by design}

Today chemists master numerous reaction pathways in their toolbox to prepare different kinds of nanobricks among oxides, polycation oxides, metal, nitrides, sulphides, phospides, clays, carbon based ma terials with an advanced control over composition, structure, size, morphology, surface properties... However, the particular cases of su percritical fluid processes for nanomaterials synthesis still suffer from some limitations. First, the advantages of high supersaturation reached at supercritical conditions have been largely employed for accessing small sizes and narrow particles size distributions. Therefore, when considering single step processes, the growth mechanism is rather weak compared to nucleation. This makes it challenging to achieve large ( $>100 \mathrm{~nm}$ ) particles. Then, advanced nanostructured materials cannot be easily obtained with a single initial precursor solution, which limits drastically the accessible architectures and reduces the ability to access complex multifunctional materials. Indeed, one can only play on the difference of reactivity between precursors to achieve multi materials nanostructures.

To address these limitations, it is desirable to consider one pot multi steps processes, as schematized in Fig. 9, for providing ways to include multi injection and multi temperature systems. Such ap proaches allow:

(i) Separating each steps of the synthesis process and controlling them finely. In particular, it is possible to control the precursor con centration and the solvent composition and therefore the super saturation to either sustain nucleation or oppositely to favour growth process for accessing core shell structures,

(ii) Separating nucleation \& growth from functionalization steps, pre venting undesirable effects of ligands over the materials nucleation and growth of the core materials,

(iii) Monitoring and analysing the materials between each steps thanks to in situ characterization techniques,

(iv) Providing fast screening capability, which can be used in process intensification.

(v) All these advantages make it possible to think about the design of more complex materials with different functionalities.

As described in Fig. 9, we can imagine one process modulus per nature of material, which has to be formed and after the mastering of homogeneous and/or heterogeneous nucleation \& growth will allow to prepare the targeted architecture. As an illustration, the reactor 1 can 

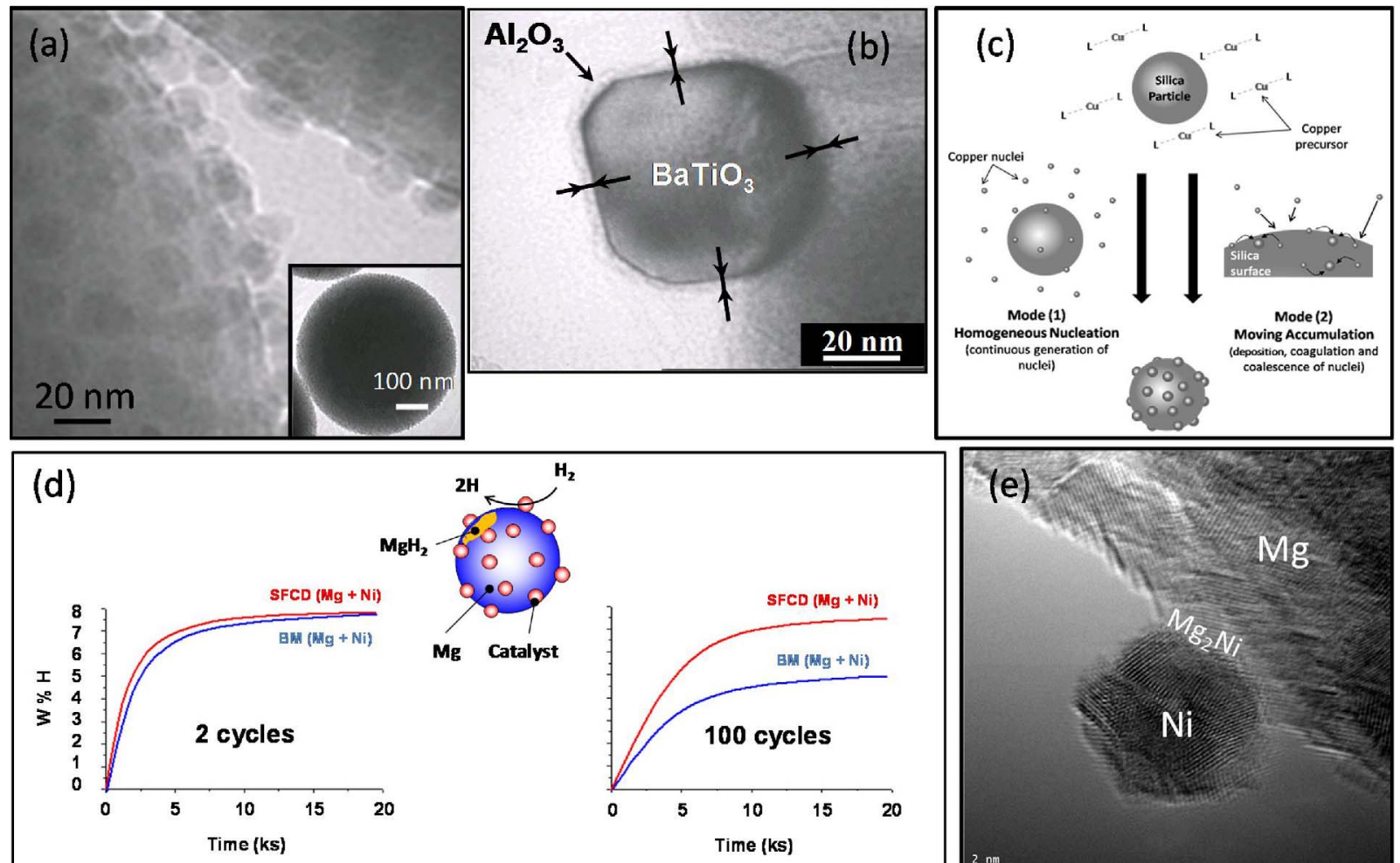

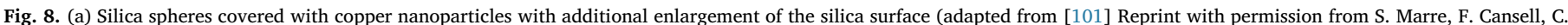

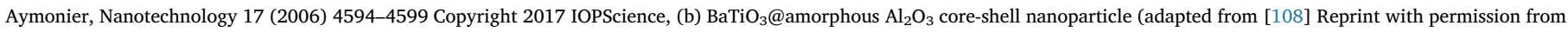

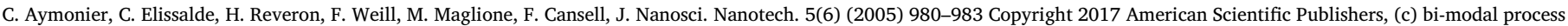

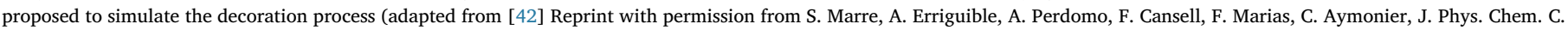

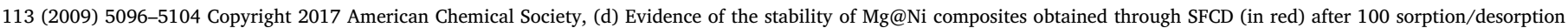

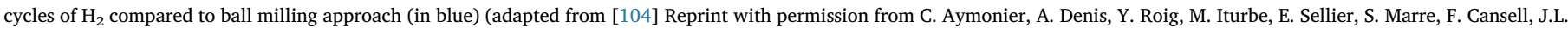

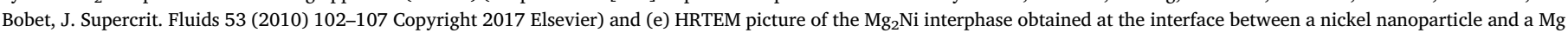

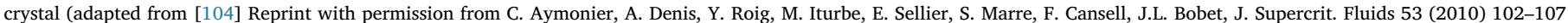
Copyright 2017 Elsevier). (For interpretation of the references to colour in this figure legend, the reader is referred to the web version of this article.)

serve at synthesizing nanostructures, which can be over coated with an inorganic shell in a second reactor and eventually with an organic shell in a third reactor. As aforementioned, the technological developments associated to advanced characterization tools can allow in situ/online characterization(s) to control and to optimize all the process para meters.

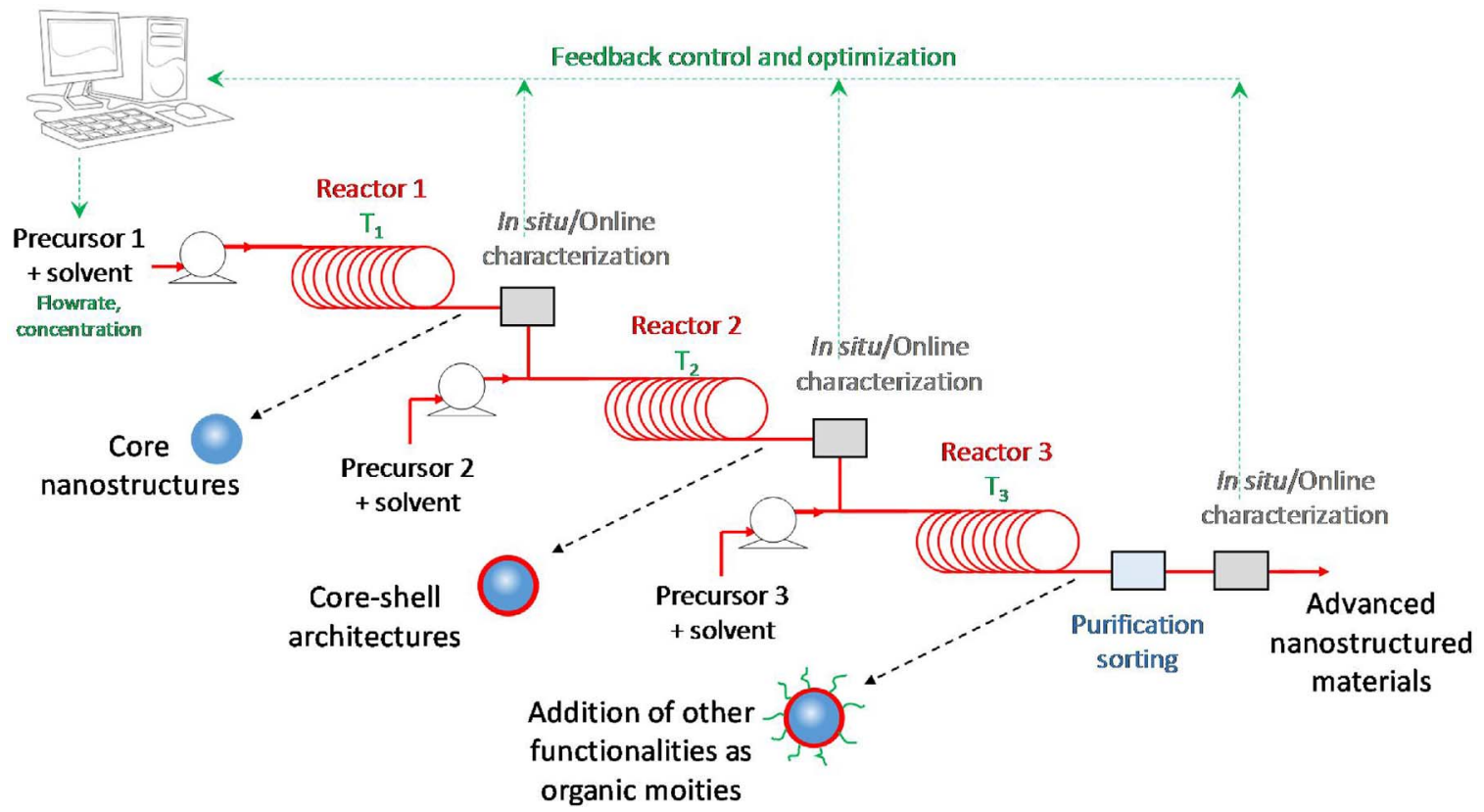

Fig. 9. Scheme of a one pot multistep process for the synthesis of advanced materials by design. 
This perspective concept has already been demonstrated by few examples in the literature for instance by Iversen et al. though a dual stage continuous flow reactor for the synthesis of hybrid nanoparticles $[109,110]$. This reactor is based on the association of two SHFS pro cesses as described in Fig. 1a. The concept of the dual stage continuous flow reactor was illustrated with the preparation of $\mathrm{TiO}_{2} @ \mathrm{SnO}_{2}, \mathrm{TiO}_{2} @$ $\mathrm{SiO}_{2}, \gamma \mathrm{Fe}_{2} \mathrm{O}_{3} @ \mathrm{SiO}_{2}$ and $\alpha \mathrm{Fe}_{2} \mathrm{O}_{3} @ \mathrm{SiO}_{2}$ core shell nanoparticles. This concept was also proposed by Zielke et al. where a two stage con tinuous hydrothermal flow synthesis reactor was designed using two different types of mixers based on CFD simulation [7]: co flow mixing for stage 1 inspired from [17] and counter flow mixing inspired from [3]. The authors synthesized YSZ NiO nanopowders for application in SOFC. In our group we have demonstrated the versatility of this concept with the preparation of functional Layered Double Hydroxide (LDH) [111]. First the possibility to produce in a continuous process small and highly crystalline LDH nanoparticles with lateral dimensions below $100 \mathrm{~nm}$ and a thickness below $20 \mathrm{~nm}$ has been achieved in only $5 \mathrm{~s}$ with different compositions by varying the cation $(\mathrm{Mg}, \mathrm{Ni}$, or $\mathrm{Zn})$ and the anion $\left(\mathrm{CO}_{3}, \mathrm{NO}_{3}\right)$. The one pot multistep process has allowed obtaining hybrid LDH with a controlled basal distance, bio hybrid LDH by the functionalization of LDH with enzymes or still catalysts thanks to the deposition of Pd and Ru nanoparticles on a LDH support.

Beyond the design of advanced nanostructured materials, this very promising concept needs to be deeply investigated because the control of the synthesis depends on the mastering of the hydrodynamic and thermal characteristics of the reactors, on the mastering of the chemical reactivity but also on the nucleation \& growth phenomena.

\section{Acknowledgements}

The authors acknowledge CNRS, the University of Bordeaux and Bordeaux INP but also the "Région Nouvelle Aquitaine" for their fi nancial support.

\section{References}

[1] T. Adschiri, K. Kanazawan, K. Arai, Rapid and continuous hydrothermal crystallization of metal oxide particles in supercritical water, J. Am. Ceram. Soc. 75 (4) (1992) 1019-1022.

[2] J.A. Darr, J. Zhang, N.M. Makwana, X. Weng, Continuous hydrothermal synthesis of inorganic nanoparticles, Chem. Rev. 117 (2017) 11125-11238.

[3] E. Lester, P. Blood, J. Denyer, D. Giddings, B. Azzopardi, M. Poliakoff, Reaction engineering: the supercritical water hydrothermal synthesis of nano-particles, J. Supercrit. Fluids 37 (2006) 209-214.

[4] S.I. Kawasaki, K. Sue, R. Ookawara, Y. Wakashima, A. Suzuki, Y. Hakuta, K. Arai, Engineering study of continuous supercritical hydrothermal method using a Tshaped mixer: experimental synthesis of $\mathrm{NiO}$ nanoparticles and CFD simulation, J. Supercrit. Fluids 54 (1) (2010) 96-102.

[5] T. Aizawa, Y. Masuada, K. Minami, M. Kanakubo, H. Nanjo, R.L. Smith, Direct observation of channel-tee mixing of high-temperature and high-pressure water, J. Supercrit. Fluids 43 (2007) 222-227.

[6] K. Sugioka, K. Ozawa, T. Tsukada, S. Takami, T. Adschiri, K. Sugimoto, N. Takenaka, Y. Saito, Neutron radiography and numerical simulation of mixing behavior in a reactor for supercritical hydrothermal synthesis, AIChE J. 60 (2014) 1168-1175.

[7] P. Zielke, Y. Xu, S.B. Simonsen, P. Norby, R. Kiebach, Simulation, design and proof-of-concept of a two-stage continuous hydrothermal flow synthesis reactor for synthesis of functionalized nano-sized inorganic composite materials, J. Supercrit. Fluids 117 (2016) 1-12.

[8] F. Cansell, B. Chevalier, A. Demourgues, J. Etourneau, C. Even, V. Pessey, S. Petit, A. Tressaud, F. Weill, J. Mater. Chem. 9 (1999) 67-75.

[9] F. Cansell, C. Aymonier, A. Loppinet-Serani, Review on materials science and supercritical fluids, Curr. Opin. Solid State Mater. Sci. 7 (2003) 331-340.

[10] C. Aymonier, A. Loppinet-Serani, H. Reveron, Y. Garrabos, F. Cansell, Review of supercritical fluids in organic materials science, J. Supercrit. Fluids 38 (2006) 242-251.

[11] F. Cansell, C. Aymonier, Design of functional nanostructured materials using supercritical fluids, J. Supercrit. Fluids 47 (2009) 508-516.

[12] S. Desmoulins-Krawiec, C. Aymonier, A. Loppinet-Serani, F. Weill, S. Gorsse, J. Etourneau, F. Cansell, Synthesis of nanostructured materials in supercritical ammonia: nitrides, metals and oxides, J. Mater. Chem. 14 (2004) 228-232.

[13] H. Jensen, M. Bremholm, R.P. Nielsen, K.D. Joensen, J.S. Pedersen, H. Birkedal, Y.S. Chen, J. Almer, E.G. Sogaard, S.B. Iversen, B.B. Iversen, In situ high-energy synchrotron radiation study of sol-gel nanoparticle formation in supercritical fluids, Angew. Chem. Int. Ed 46 (2007) 1113-1116.
[14] J. Becker, M. Bremholm, C. Tyrsted, B. Pauw, K.M.Ø. Jensen, J. Eltzholt, M. Christensen, B.B. Iversen, Experimental setup for in situ X-ray SAXS/WAXS/PDF studies of the formation and growth of nanoparticles in near- and supercritical fluids, J. Appl. Crystallogr. 43 (2010) 729-736.

[15] D. Testemale, R. Argoud, O. Geaymond, J.-L. Hazemann, High pressure/high temperature cell for x-ray absorption and scattering techniques, Rev. Sci. Instrum. 76 (2005) 043905

[16] M. Louvel, A. Bordage, C. Da Silva-Cadoux, D. Testemale, E. Lahera, W. Del Net, O. Geaymond, J. Dubessy, R. Argoud, J.-L. Hazemann, A high-pressure hightemperature set-up for in situ Raman spectroscopy of supercritical fluids, J. Mol. Liq. 205 (2015) 54-60.

[17] Y. Roig, S. Marre, T. Cardinal, C. Aymonier, Synthesis of exciton luminescent ZnO nanocrystals using continuous supercritical microfluidics, Angew. Chem. Int. Ed. 50 (2011) 12071-12074.

[18] T. Gendrineau, S. Marre, M. Vaultier, M. Pucheault, C. Aymonier, Microfluidic synthesis of palladium nanocrystals assisted by supercritical CO2: tailored surface properties for applications in boron chemistry, Angew. Chem. Int. Ed. 51 (2012) $8525-8528$.

[19] O. Pascu, L. Marciasini, S. Marre, M. Vaultier, M. Pucheault, C. Aymonier, Continuous coflow synthesis of hybrid palladium nanocrystals as catalysts for borylation reaction, Nanoscale 5 (2013) 12425-12431.

[20] S. Marre, A. Adamo, S. Basak, C. Aymonier, K.F. Jensen, Design and packaging of microreactors for high pressure and high temperature applications, Ind. Eng. Chem. Res. 49 (2010) 11310-11320.

[21] S. Marre, Y. Roig, C. Aymonier, Supercritical microfluidics: opportunities in flowthrough chemistry and materials science, J. Supercrit. Fluids 66 (2012) 251-264.

[22] S. Marre, J. Park, J. Rempel, J. Guan, M.G. Bawendi, K.F. Jensen, Supercritical continuous-microflow synthesis of narrow size distribution quantum dots, Adv. Mater. 20 (2008) 4830-4834.

[23] S. Marre, J. Baek, J. Park, M.G. Bawendi, K.F. Jensen, High-pressure/high-temperature microreactors for nanostructure synthesis, Jala 14 (2009) 367-373.

[24] S. Marre, K.F. Jensen, Synthesis of micro and nanostructures in microfluidic systems, Chem. Soc. Rev. 39 (2010) 1183-1202.

[25] R. Couto, S. Chambon, C. Aymonier, E. Mignard, B. Pavageau, A. Erriguible, S. Marre, Microfluidic supercritical antisolvent continuous processing and direct spray-coating of poly-(3-hexylthiophene) nanoparticles for OFET devices, Chem. Commun. 51 (2015) 1008-1011.

[26] A.-C. Dippel, K.M. Jensen, C. Tyrsted, M. Bremholm, E.D. Bøjesen, D. Saha, S. Birgisson, M. Christensen, S.J.L. Billinge, B.B. Iversen, Towards atomistic understanding of polymorphism in the solvothermal synthesis of $\mathrm{ZrO} 2$ nanoparticles, Acta Crystallogr. 72 (2016) 645-650.

[27] E.D. Bøjesen, K.M. Jensen, C. Tyrsted, A. Mamakhel, H.L. Andersen, H. Reardon, J. Chevalier, A.-C. Dippel, B.B. Iversen, The chemistry of ZnWO4 nanoparticle formation, Chem. Sci 7 (2016) 6394-6406.

[28] D. Saha, E.D. Bøjesen, K.M.ø. Jensen, A.C. Dippel, B.B. Iversen, Formation mechanisms of Pt and Pt3Gd nanoparticles under solvothermal conditions: an in situ total X-ray scattering study, J. Phys. Chem. C 119 (2015) 13357-13362.

[29] G. Philippot, K.M. Jensen, M. Christensen, C. Elissalde, M. Maglione, Iversen, C. Aymonier, Growth mechanism of $\mathrm{Ba}_{1} \mathrm{Sr}_{\mathrm{x}} \mathrm{TiO}_{3}(0 \leq \mathrm{x} \leq 1)$ nanoparticles in supercritical water/ethanol mixtures, J. Supercrit. Fluids 87 (2014) 111-117.

[30] G. Philippot, E.D. Boejesen, C. Elissalde, M. Maglione, C. Aymonier, B.B. Iversen Insights into BaTi1-y $\mathrm{Zr} \mathrm{y} \mathrm{O}_{3}(0 \leq \mathrm{y} \leq 1)$ synthesis under supercritical fluid conditions, Chem. Mater. 28 (2016) 3391-3400.

[31] C. Tyrsted, B.R. Pauw, Jensen KM $\varnothing$, J. Becker, M. Christensen, B.B. Iversen, Watching nanoparticles form: an in situ (small-/wide-angle X-ray scattering/total scattering) study of the growth of yttria-stabilised zirconia in supercritical fluids, Chem. Eur. J. 18 (2012) 5759-5766.

[32] D. Testemale, M.-V. Coulet, J.-L. Hazemann, J.-P. Simon, F. Bley, O. Geaymond, R. Argoud, Small angle X-ray scattering of a supercritical electrolyte solution: the effect of density fluctuations on the hydration of ions, J. Chem. Phys. 122 (2005) 194505.

[33] C. Da Silva, O. Proux, J.-L. Hazemann, J. James-Smith, D. Testemale, T. Yamaguchid, X-ray absorption spectroscopy study of solvation and ion-pairing in aqueous gallium bromide solutions at supercritical conditions, J. Mol. Liq. 147 (2009) 83-95.

[34] V. Ranieri, J. Haines, O. Cambon, C. Levelut, R. Le Parc, M. Cambon, J. L. Hazemann, In situ X-ray absorption spectroscopy study of $\mathrm{Si}_{1} \mathrm{Ge}_{\mathrm{x}} \mathrm{O}_{2}$ dissolution and germanium aqueous speciation under hydrothermal conditions, Inorg. Chem. 51 (2012) 414-419.

[35] M. Souleiman, O. Cambon, A. Haidoux, J. Haines, C. Levelut, V. Ranieri, J.L. Hazemann, Study of $\mathrm{Ga}^{3+}$-induced hydrothermal crystallization of an alphaquartz type $\mathrm{Ga}_{1}{ }_{\mathrm{x}} \mathrm{Fe}_{\mathrm{x}} \mathrm{PO}_{4}$ single crystal by in situ X-ray absorption spectroscopy (XAS), Inorg. Chem. 51 (2012) 11811-11819.

[36] T. Beuvier, E.A.C. Panduro, P. Kwasniewski, S. Marre, C. Lecoutre, Y. Garrabos, C. Aymonier, B. Calvignac, A. Gibaud, Implementation of in situ SAXS/WAXS characterization into silicon/glass microreactors, Lab Chip 15 (2015) 2002-2008.

[37] N. Liu, C. Aymonier, C. Lecoutre, Y. Garrabos, S. Marre, Microfluidic approach for studying $\mathrm{CO}_{2}$ solubility in water and brine using confocal Raman spectroscopy, Chem. Phys. Lett. 551 (2012) 139-143.

[38] S. Marre, C. Aymonier, P. Subra, E. Mignard, Dripping to jetting transitions observed from supercritical fluid in liquid microcoflows, Appl. Phys. Lett. 95 (2009) (134105-1-134105-3).

[39] R. Guillaument, A. Erriguible, C. Aymonier, S. Marre, P. Subra-Paternault, Numerical simulation of dripping and jetting in supercritical fluids/liquid micro coflows, J. Supercrit. Fluids 81 (2013) 15-22.

[40] H.M. Hulburt, S. Katz, Some problems in particle technology: a statistical 
mechanical formulation, Chem. Eng. Sci. 19 (1964) 555-574.

[41] A. Erriguible, F. Marias, F. Cansell, C. Aymonier, Monodisperse model to predict the growth of inorganic nanostructured particles in supercritical fluids through a coalescence and aggregation mechanism, J. Supercrit. Fluids 48 (2009) 79-84.

[42] S. Marre, A. Erriguible, A. Perdomo, F. Cansell, F. Marias, C. Aymonier, Kinetically controlled formation of supported nanoparticles in low temperature supercritical media for the development of advanced nanostructured materials, J. Phys. Chem. C. 113 (2009) 5096-5104.

[43] J. Sierra-Pallares, E. Alonso, I. Montequi, M.J. Cocero, Particle diameter prediction in supercritical nanoparticle synthesis using three-dimensional CFD simulations. Validation for anatase titanium dioxide production, Chem. Eng. Sci. 64 (2009) 3051-3059.

[44] T. Adschiri, S. Takami, M. Umetsu, T. Tsukada, Hydrothermal synthesis at supercritical conditions: experiments and simulation, Sixth Int. Symp. Supercrit. Fluids Versailles, France, 2003, p. 30.

[45] K. Sue, T. Adschiri, K. Arai, Predictive model for equilibrium constants of aqueous inorganic species at subcritical and supercritical conditions, Ind. Eng. Chem. Res. 41 (2002) 3298-3306.

[46] E.L. Shock, H.C. Helgeson, Calculation of the thermodynamic and transport properties of aqueous species at high pressures and temperatures: correlation algorithms for ionic species and equation of state predictions to $5 \mathrm{~kb}$ and $1000^{\circ} \mathrm{C}$, Geochim. Cosmochim. Acta 52 (1988) 2009-2036.

[47] M. Chen, C.Y. Ma, T. Mahmud, J.A. Darr, X.Z. Wang, Modelling and simulation of continuous hydrothermal flow synthesis process for nano-materials manufacture, J. Supercrit. Fluids 59 (2011) 131-139.

[48] C.Y. Ma, M. Chen, X.Z. Wang, Modelling and simulation of counter-current and confined jet reactors for hydrothermal synthesis of nano-materials, Chem. Eng. Sci. 109 (2014) 26-37

[49] L. Zhou, S. Wang, D. Xu, Y. Guo, Impact of mixing for the production of CuO nanoparticles in supercritical hydrothermal synthesis, Ind. Eng. Chem. Res. 53 (2014) 481-493.

[50] A. Leybros, R. Piolet, M. Ariane, H. Muhr, F. Bernard, F. Demoisson, CFD simulation of $\mathrm{ZnO}$ nanoparticle precipitation in a supercritical water synthesis reactor, J. Supercrit. Fluids 70 (2012) 17-26.

[51] F. Masoodiyeh, M.R. Mozdianfard, J. Karimi-Sabet, Modeling zirconia nanoparticles prepared by supercritical water hydrothermal synthesis using population balance equation, Powder Technol. 317 (2017) 264-274.

[52] T. Voisin, A. Erriguible, G. Philippot, D. Ballenghien, D. Mateos, F. Cansell, B.B. Iversen, C. Aymonier, Investigation of the precipitation of Na2SO4 in supercritical water, Chem. Eng. Sci. 174 (2017) 268-276.

[53] S. Amiroudine, J.-P. Caltagirone, A. Erriguible, A Lagrangian-Eulerian compressible model for the trans-critical path of near-critical fluids, IJMF 59 (2014) 15-23.

[54] VDI Heat Atlas, 2nd edition, Springer-Verlag, Berlin, 2010.

[55] NIST database, www.nist.gov.

[56] A.R. Bazaev, M. Abdulagatov, E.A. Bazaev, A. Abdurashidova, (p, v, T, x) measurements of $\left((1-x) \mathrm{H}_{2} \mathrm{O}+\mathrm{xC}_{2} \mathrm{H}_{5} \mathrm{OH}\right)$ mixtures in the near-critical and supercritical regions, J. Chem Thermodyn. 39 (3) (2007) 385-411.

[57] B. Pinho, S. Girardon, F. Bazer-Bachi, G. Bergeot, S. Marre, C. Aymonier, A microfluidic approach for investigating multicomponent systems thermodynamics at high pressures and temperatures, Lab Chip 14 (19) (2014) 3843-3849.

[58] T. Adschiri, Supercritical hydrothermal synthesis of organic-inorganic hybrid nanoparticles, Chem. Lett. 36 (2007) 1188-1193.

[59] M.D. Tercero, M. Bruns, I.G. Martínez, M. Türk, U. Fehrenbacher, S. Jennewein, L. Barner, Continuous hydrothermal synthesis of In situ functionalized iron oxide nanoparticles: a general strategy to produce metal oxide nanoparticles with clickable anchors, Part. Part. Syst. Charact. 30 (2013) 229-234.

[60] M.D. Tercero, I.G. Martínez, M. Herrmann, M. Bruns, C. Kübel, S. Jennewein, U. Fehrenbacher, L. Barner, M. Türk, Synthesis of in situ functionalized iron oxide nanoparticles presenting alkyne groups via a continuous process using near-critical and supercritical water, J. Supercrit. Fluids 82 (2013) 83-95.

[61] A. Dumas, M. Claverie, C. Slostowski, C. Le Rous, P. Micoud, F. Martin, C. Aymonier, Fast geomimicking using chemistry in supercritical water, Angew. Chem. Int. Ed. 55 (34) (2016) 9795-10149.

[62] M. Claverie, A. Dumas, C. Careme, M. Poirier, C. Le Roux, P. Micoud, F. Martin C. Aymonier, Synthetic talc and talc-like structures: preparation, features and applications, Chem. Eur. J. (2017), http://dx.doi.org/10.1002/chem.201702763.

[63] M. Diez-Garcia, J.J. Gaitero, J.S. Dolado, C. Aymonier, Ultra-fast tobermorite supercritical hydrothermal synthesis under thermodynamically metastable conditions, Angew. Chem. Int. Ed. 56 (2017) 1-6.

[64] M. Faustini, D. Grosso, C. Boissière, R. Backov, C. Sanchez, Integrative sol-gel chemistry: a nanofoundry for materials science, J. Sol-Gel Sci. Technol. 70 (2) (2014) 216-226

[65] J.F. Bocquet, K. Chhor, C. Pommier, Barium titanate powders synthesis from solvothermal reaction and supercritical treatment, Mater. Chem. Phys. 57 (1999) 273-280.

[66] H. Reveron, C. Aymonier, A. Loppinet-Serani, C. Elissalde, M. Maglione, F. Cansell, One-pot synthesis of well-crystallized and pure barium titanate nanoparticles in supercritical fluids, Nanotechnology 16 (2005) 1137-1143.

[67] H. Reveron, C. Elissalde, C. Aymonier, M. Maglione, F. Cansell, Continuous synthesis of well-crystallized BST nanoparticles under supercritical conditions and its ferroelectric properties, J. Nanosci. Nanotech. 5 (10) (2005) 1741-1744.

[68] G. Philippot, C. Elissalde, M. Maglione, C. Aymonier, Supercritical fluid technology: a reliable process for high quality $\mathrm{BaTiO}_{3}$ based nanomaterials, Adv. Powder Technol. 25 (5) (2014) 1415-1429.

[69] G. Philippot, M. Albino, U.-C. Chung, M. Josse, C. Elissalde, M. Maglione, C. Aymonier, Continuous $\mathrm{BaTi}_{1 \mathrm{y}} \mathrm{Zr}_{\mathrm{y}} \mathrm{O}_{3}(0 \leq \mathrm{y} \leq 1)$ nanocrystals synthesis in supercritical fluids for nanostructured lead-free ferroelectric ceramics, Mater. Design 86 (2015) 354-360.

[70] G. Philippot, M. Albino, R. Epherre, G. Chevallier, Y. Beynet, C. Manière, A. Weibel, A. Peigney, M. Deluca, C. Elissalde, M. Maglione, C. Aymonier, C. Estournès, Local distortions in nanostructured ferroelectric ceramics through strain tuning, Adv. Electron. Mater. 1 (2015) 1500190.

[71] M. Tsang, G. Philippot, C. Aymonier, G. Sonnemann, Anticipatory life-cycle assessment of supercritical fluid synthesis of barium strontium titanate nanoparticles, Green Chem. 18 (2016) 4924-4933.

[72] N. Lock, M. Christensen, K.M. Ø Jensen, B.B. Iversen, Rapid one-step low-temperature synthesis of nanocrystalline $\gamma-\mathrm{Al}_{2} \mathrm{O}_{3}$, Angew. Chem. Int. Ed. 50 (2011) 7045-7047.

[73] C. Slostowski, S. Marre, O. Babot, T. Toupance, C. Aymonier, Near- and supercritical alcohols as solvents and surface modifiers for the continuous synthesis of cerium oxide nanoparticles, Langmuir 28 (2012) 16656-16663.

[74] M. Bondesgaard, J. Becker, J. Xavier, H. Hellstern, A. Mamakhel, B.B. Iversen, Guide to by-products formed in organic solvents under solvothermal conditions, J. Supercrit. Fluids 113 (2016) 166-197.

[75] B. Giroire, C. Slostowski, S. Marre, C. Aymonier, T. Aida, D. Hojo, N. Aoki, S. Takami, T. Adschiri, Tuning surface grafting density of $\mathrm{CeO}_{2}$ nanocrystals with near- and supercritical solvent characteristics, Phys. Chem. Chem. Phys. 18 (2016) 1727-1734.

[76] C. Slostowski, S. Marre, O. Babot, T. Toupance, C. Aymonier, Effect of thermal treatment on the textural properties of $\mathrm{CeO}_{2}$ powders synthesized in near- and supercritical alcohols, Chem. Phys. Chem. 16 (2015) 3493-3499.

[77] C. Slostowski, S. Marre, P. Dagault, O. Babot, T. Toupance, C. Aymonier, $\mathrm{CeO}_{2}$ nanopowders as solid sorbent for efficient $\mathrm{CO}_{2}$ capture/release processes, $\mathrm{J} . \mathrm{CO}_{2}$ Utilization 20 (2017) 52-58.

[78] M. Theodet, C. Quilfen, C. Martinez, C. Aymonier, Continuous supercritical synthesis of unsupported and high specific surface area catalyst precursors for deep-hydrodesulfurization, J. Supercrit. Fluids 117 (2016) 252-259.

[79] S.K. Pahari, T. Adschiri, A. Panda, Synthesis of monodispersed nanocrystalline materials in supercritical ethanol: a generalized approach, J. Mater. Chem. 21 (2011) 10377-10383.

[80] O. Pascu, S. Marre, C. Aymonier, A. Roig, Ultrafast and continuous synthesis of crystalline ferrite nanoparticles in supercritical ethanol, Nanoscale 5 (5) (2013) $2126-2132$

[81] J. Hwang, D. Yoon, B. Kweon, W. Chang, J. Kim, A simple, one-pot synthesis of molybdenum oxide reduced graphene oxide composities in supercritical methanol, RSC Adv. 6 (2016) 108298-108309.

[82] K.S. Kumar, W. Li, M. Choi, M. Kim, J. Kim, Synthesis and lithium storage properties of $\mathrm{MoS}_{2}$ nanoparticles prepared in supercritical ethanol, Chem. Eng. J. 285 (2016) 517-527.

[83] S.H. Lee, S. Park, M. Kim, D. Yoon, C. Chanthad, M. Cho, J. Kim, J.H. Park, Y. Lee Supercritical carbon dioxide-assisted process for well-dispersed silicon/graphene composite as a Li ion battery anode, Sci. Rep. 6 (2016) (32011-1-32011-9).

[84] C.-I. Wu, J.-W. Huang, Y.-L. Wen, S.-B. Wen, Y.-H. Shen, M.-Y. Yeh, Preparation of $\mathrm{TiO}_{2}$ nanoparticles by supercritical carbon dioxide, Mater. Lett. 62 (2008) 1923-1926.

[85] L.E. Pell, A.D. Schricker, F.V. Mikulec, B.A. Korgel, Synthesis of amorphous silicon colloids by trisilane thermolysis in high temperature supercritical solvents, Langmuir 20 (2004) 6546-6548.

[86] M.L. De Marco, S. Semlali, B.A. Korgel, P. Barois, G.L. Drisko, C. Aymonier, Silicon-based dielectric metamaterials: focus on the current synthesis challenges, Angew. Chem. Int Ed. (2017), http://dx.doi.org/10.1002/anie.201709044 (in press).

[87] D.C. Lee, F.V. Mikulec, B.A. Korgel, Carbon nanotube synthesis in supercritical toluene, J. Am. Chem Soc. 126 (2004) 4951-4957.

[88] S. Moisan, J.D. Marty, F. Cansell, C. Aymonier, Preparation of functional hybrid palladium nanoparticles using supercritical fluids: a novel approach to detach the growth and functionalization steps, Chem. Commun. 142 (2008) 1428-1430.

[89] H.D.S. Guerrand, L.D. Marciasini, T. Gendrineau, O. Pascu, S. Marre, S. Pinet, M. Vaultier, C. Aymonier, M. Pucheault, Sequential dehydrogenation-arylation of diisopropylamine-borane complex catalyzed by palladium nanoparticles, Tetrahedron 70 (2014) 6156-6161.

[90] O. Pascu, L. Marciasini, S. Marre, M. Vaultier, M. Pucheault, C. Aymonier, Continuous coflow synthesis of hybrid palladium nanocrystals as catalysts for borylation reaction, Nanoscale 5 (24) (2013) 12425-12431.

[91] J. Baek, P.M. Allen, M.G. Bawendi, K.F. Jensen, Investigation of indium phosphide nanocrystal synthesis using a high-temperature and high-pressure continuous flow microreactor, Angew. Chem. Int. Ed. 50 (2011) 627-630.

[92] A. Chakrabarty, S. Marre, R.F. Landis, V.M. Rotello, U. Maitra, A.D. Guerzo, C. Aymonier, Continuous synthesis of high quality CdSe quantum dots in supercritical fluids, J. Mater. Chem. C 3 (2015) 7561-7566.

[93] I. Christian, S. Benjamin, P. Christopher, K. Stefan, G. Tonino, H. Andreas, Largescale synthesis of high quality InP quantum dots in a continuous flow-reactor under supercritical conditions, Nanotechnology 26 (2015) 085604.

[94] B. Giroire, S. Marre, A. Garcia, T. Cardinal, C. Aymonier, Continuous supercritical route for quantum-confined GaN nanoparticles, React. Chem. Eng. 1 (2016) 151-155.

[95] O. Pascu, S. Marre, C. Aymonier, The role of interface in hybrid/composite nanostructured materials prepared in supercritical fluids, Nanotechnology Rev. 4 (6) (2015) 487-515.

[96] C. Erkey, Supercritical Fluids \& Organometalliccompounds, Elsevier, Amsterdam, 2011

[97] M. Türk, Particle Formation with Supercriticalfluids, Elsevier, Amsterdam, 2014 
[98] M. Majimel, S. Marre, E. Garrido, C. Aymonier, Supercritical fluid chemical deposition as an alternative process to CVD for the surface modification of materials, Chem. Vap. Deposition 17 (2011) 342-352.

[99] Y. Zhang, C. Erkey, Preparation of supported metallic nanoparticles using supercritical fluids, J. Supercrit. Fluids 38 (2006) 252-267.

[100] C. Erkey, Preparation of metallic supported nanoparticles and films using supercritical fluid deposition, J. Supercrit. Fluids 47 (2009) 517-522.

[101] S. Marre, F. Cansell, C. Aymonier, Design at the nanometre scale of multifunctional materials using supercritical fluid chemical deposition, Nanotechnology 17 (2006) 4594-4599.

[102] J.L. Bobet, C. Aymonier, D. Mesguich, F. Cansell, K. Asano, E. Akiba, Particle decoration in supercritical fluid to improve the hydrogen sorption cyclability of magnesium, J. Alloys Comp. 429 (2007) 250-254.

[103] A. Denis, E. Sellier, C. Aymonier, J.L. Bobet, Hydrogen sorption properties of magnesium particles decorated with metallic nanoparticles as catalyst, J. Alloys Comp. 476 (2009) 152-159.

[104] C. Aymonier, A. Denis, Y. Roig, M. Iturbe, E. Sellier, S. Marre, F. Cansell, J.L. Bobet, Supported metal NPs on magnesium using SCFs for hydrogen storage: interface and interphase characterization, J. Supercrit. Fluids 53 (2010) 102-107.

[105] O. Pascu, B. Cacciuttolo, S. Marre, M. Pucheault, C. Aymonier, $\mathrm{ScCO}_{2}$ assisted preparation of supported metal NPs Application to catalyst design, J. Supercrit.
Fluids 105 (2015) 84-91

[106] B. Motos, D. Uzio, C. Aymonier, Preparation of nickel phosphide hydrodesulfurization catalysts assisted by supercritical carbon dioxide, ChemCatChem 7 (2015) 3441-3444.

[107] B. Motos, C. Quilfen, D. Uzio, C. Aymonier, Supercritical $\mathrm{CO}_{2}$ assisted preparation of supported Molybdenum phosphide for hydrotreating catalysis, ChemCatChem 9 (2017) 2352-2357.

[108] C. Aymonier, C. Elissalde, H. Reveron, F. Weill, M. Maglione, F. Cansell, Supercritical fluid technology of nanoparticles coating for new ceramic materials, J. Nanosci. Nanotech. 5 (6) (2005) 980-983.

[109] H.L. Hellstern, J. Becker, P. Hald, M. Bremholm, A. Mamakhel, B.B. Iversen, Development of a dual-stage continuous flow reactor for hydrothermal synthesis of hybrid nanoparticles, Ind. Eng. Chem. Res. 54 (2015) 8500-8508.

[110] H.L. Hellstern, A. Mamakhel, M. Bremholm, B.B. Iversen, Core-shell nanoparticles by silica coating of metal oxides in a dual-stage hydrothermal flow reactor, Chem. Commun. 52 (2016) 3434-3437.

[111] O. Pascu, S. Marre, B. Cacciuttolo, G. Ali, L. Hecquet, M. Pucheault, V. Prevot, C. Aymonier, Instant one-pot preparation of functional layered double hydroxides (LDHs) via a continuous hydrothermal approach, ChemNanoMat 3 (2017) 614-619. 